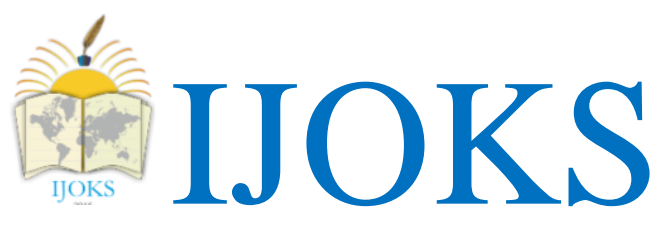

International Journal of Kurdish Studies

(ISSN:2149-2751)

5 (1), pp. $290-311$

http://www.ijoks.com

\title{
The application of 1958 and 1970 Agrarian Reform Acts in HawlerLiwa (Governorate) and its effects a historical study
}

\section{Khalil Ali MURAD ${ }^{1} \&$ Burhan Hatam OTHMAN ${ }^{2}$}

Received: Oct 28, 2018 Reviewed: Nov 29, 2018 Accepted: Dec 02, 2018

\begin{abstract}
The 14th of July in 1958 was a turning point in the history of contemporary Iraq politically, socially, and economically. One of the main changes was the acquisition of agricultural lands through the enactment of the "Agrarian Reform Act" in 1958, which remained in place until the enactment of another act, the Agrarian Reform Act of 1970. These laws aimed to put an end to large ownership of agricultural land in Iraq by distributing it among the farmers. This study aims to highlight the application of the two acts and their effects on the governorate (Liwa) of Hawler (Erbil). It approaches the subject through two different topics.

The first one tackles the application of 1958 Agrarian Reform Act in Hawler governorate. We analyze the main articles of the $1958 \mathrm{act}$, and then discuss the land ownership in the governorate, the area of lands confiscated from landlords, and the process of distributing those lands to the peasants. This sectionalso highlights the effects of land distribution on production relations before looking at the effects of the Kurdish Revolt of September 1961 on the application of the Agrarian Reform Act of 1958.

The second topic is devoted to analyzing the application of the Agrarian Reform Act of 1970 in Hawler governorate in the same way as the first topic; we also note some differences between the two acts, while looking also at the area of the land that was distributed and the number of beneficiaries in the Hawler governorate. This topic also focuses on some of the shortcomings of the 1970 Act, especially nothing that some of its articles did not take into account the specific situation in Kurdistan.
\end{abstract}

Key words: Agrarian Reform Acts, Kurds, HawlerLiwa, Governorate, Contemporary Iraq, Erbil

\section{Recommended citation:}

Murad, K.A. \& Othman, B.H. (2019). The application of 1958 and 1970 Agrarian Reform Acts in HawlerLiwa (Governorate) and its effects a historical study. International Journal of Kurdish Studies 5 (1), 290 - 311 DOI: 10.21600/ijoks.516510

\footnotetext{
${ }^{1} \mathrm{Ph}$. D, Lecture, Department of History, of College of Arts, Salahaddin University, Erbil, Kirkuk Road, KRG, Iraq. E-mail: drkhalil ali@yahoo.com,

${ }^{2}$ Correspondent Author: A.T, Lecture, Department of History, of College of Arts, Salahaddin University-Erbil, Kirkuk Road, KRG, Iraq. E-mail: burhann atam@yahoo.com, ORCID NO : https://orcid.org/0000-0002-76090634
} 


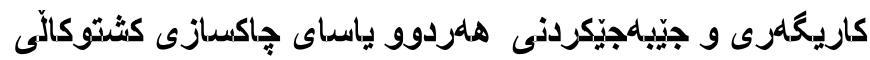 \\ سالّى 1958 و 1970 له ليوا (ياريزيَا) ى هلوليّز \\ ليّكوَلْينهوهيلكى ميّزووييه
}

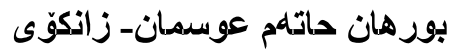

خلفيل علذى موراد- زانكوّى سدلّاحهدين

سدالעاحdدين

بوخته

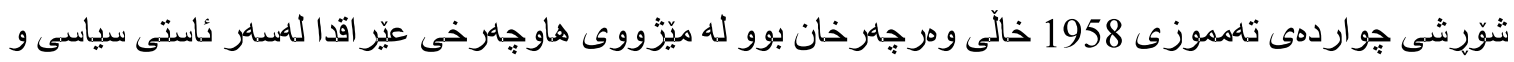

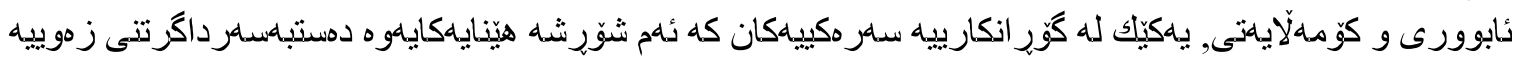

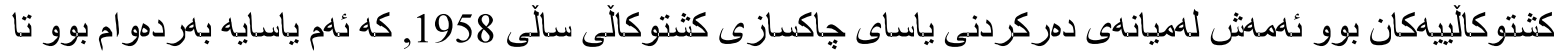

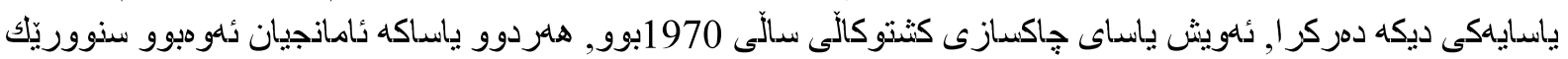

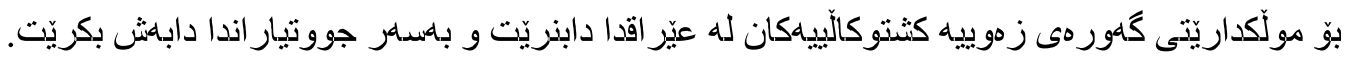

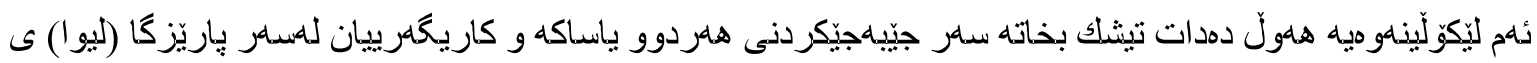

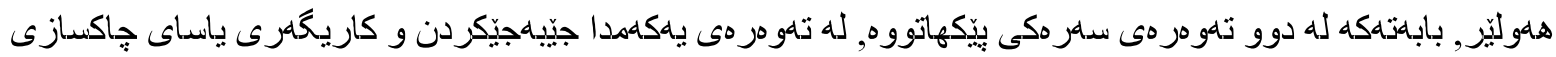

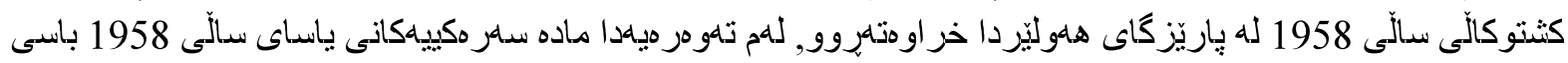

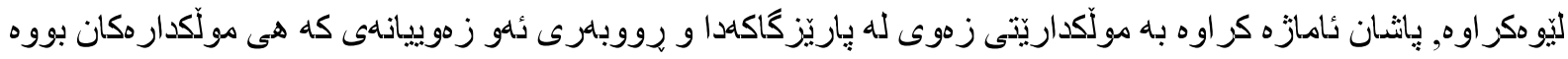

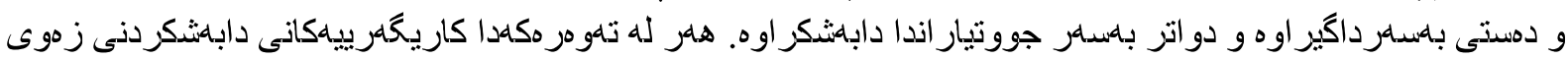

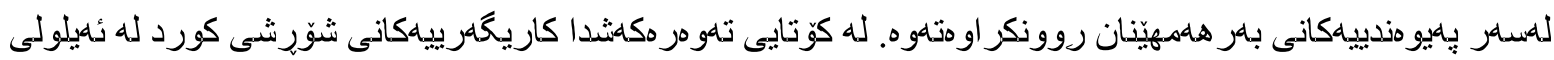

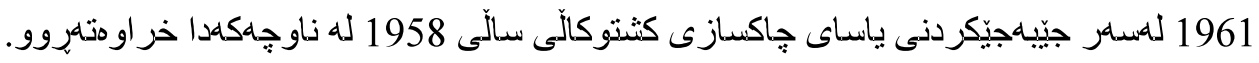

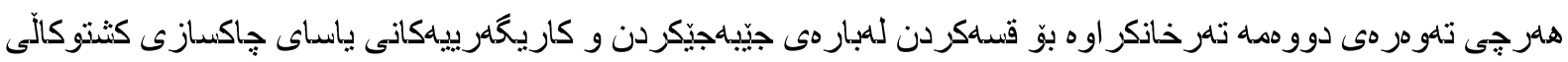

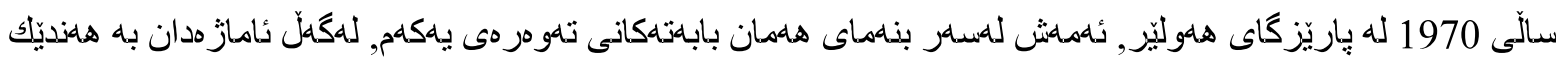

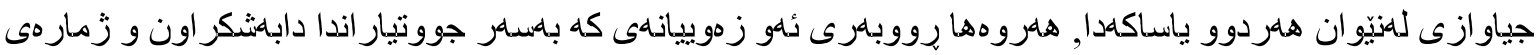

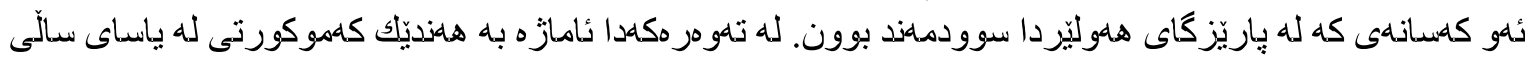

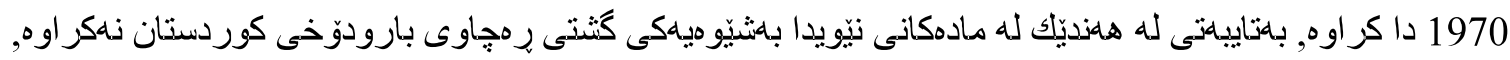
لهنيّو يشياندا هلهوليّر.

بِيَشْكى

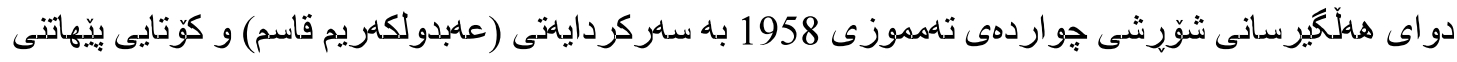

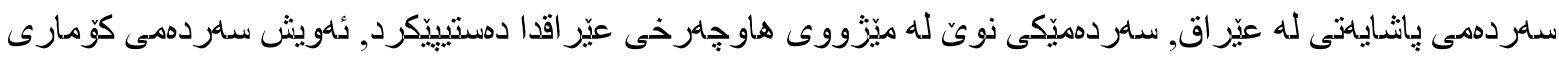

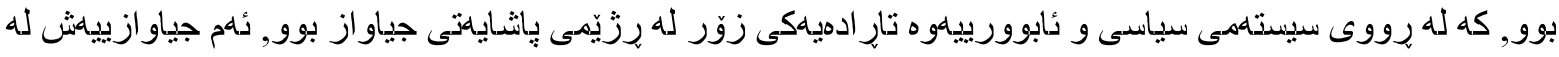

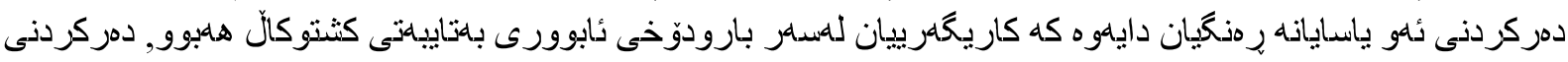

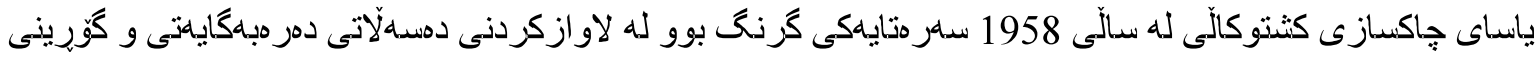

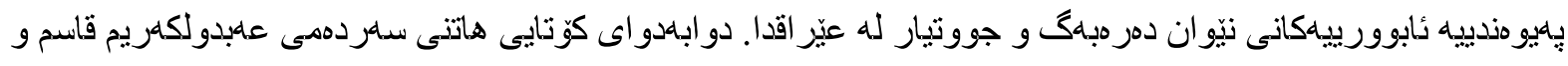

International Journal of Kurdish Studies Vol.5/1 ( January 2019) 


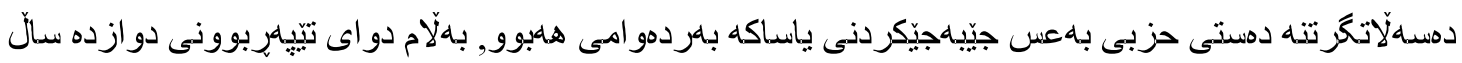

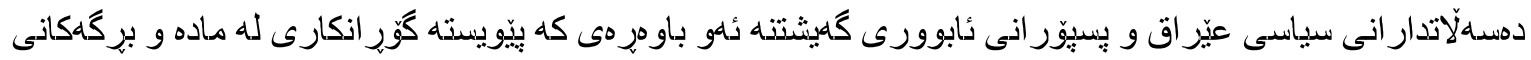

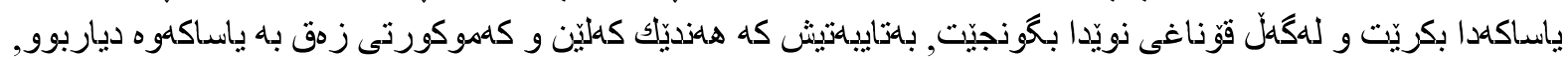

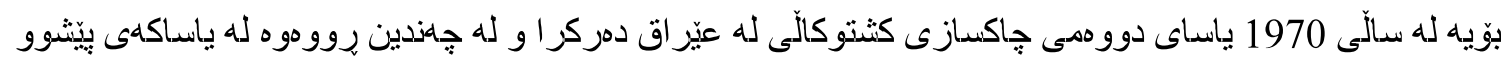

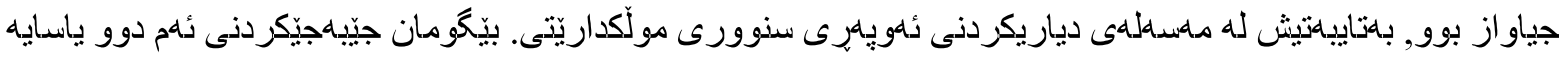

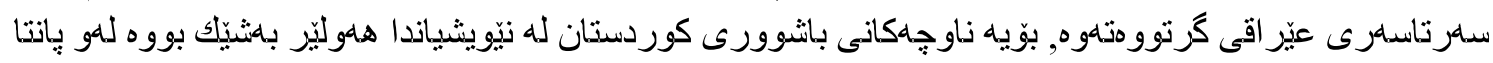

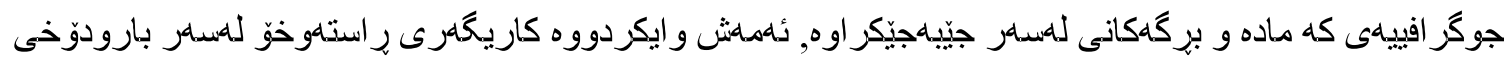

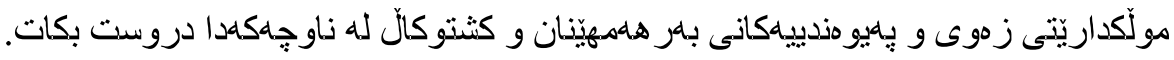

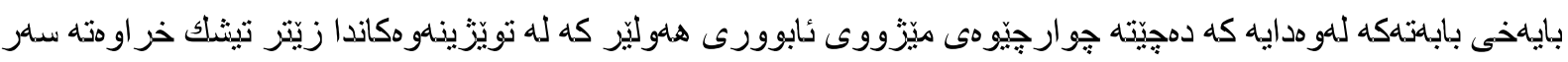

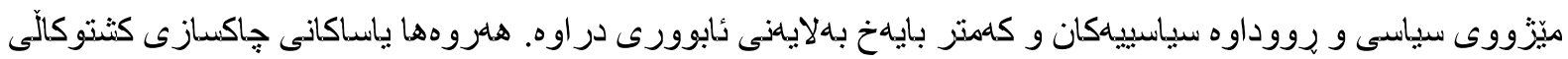

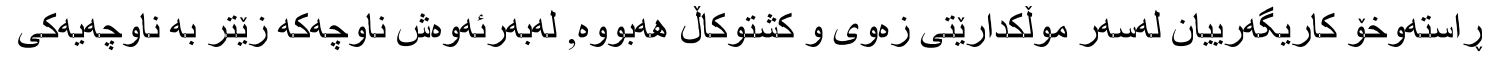

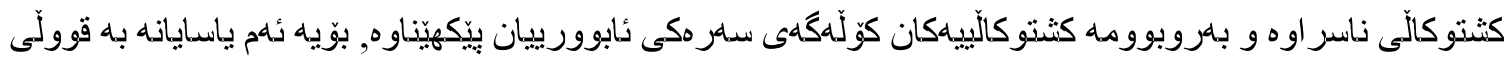

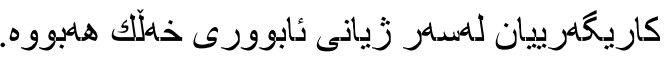

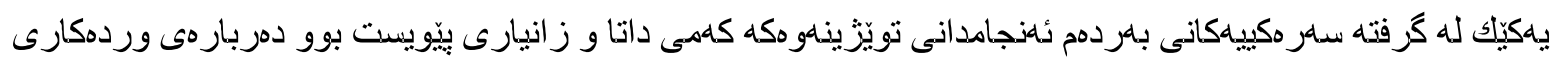

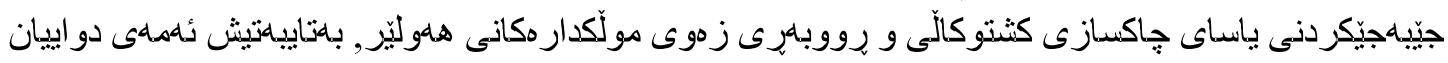

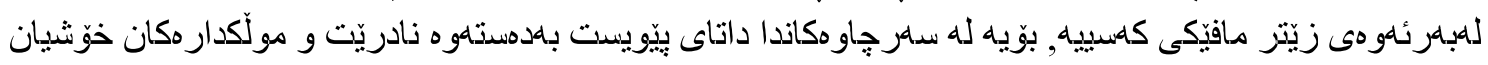

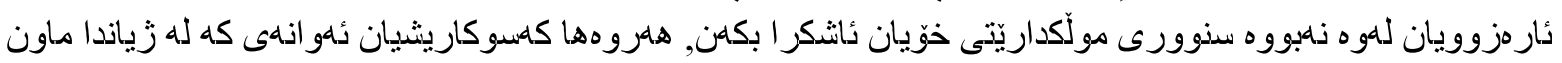

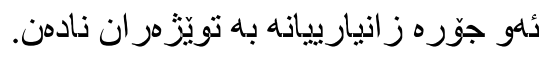

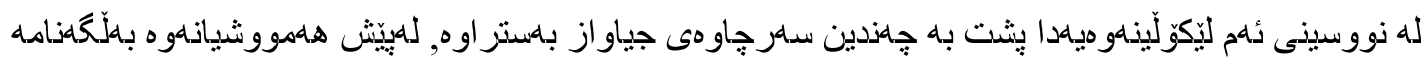

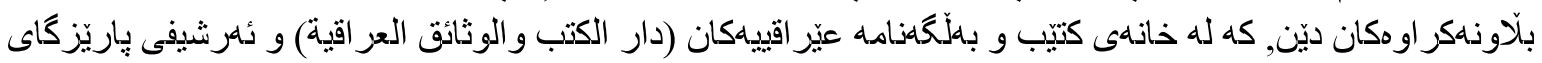

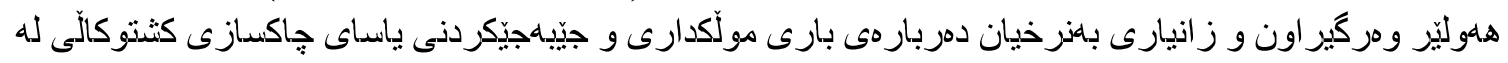

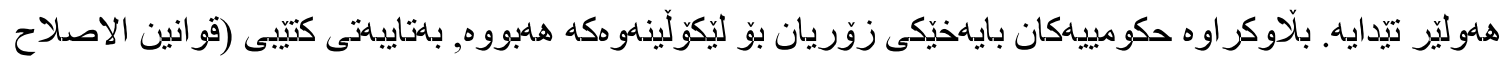

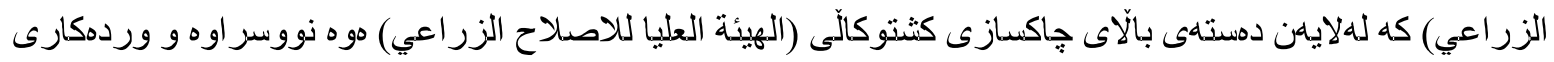

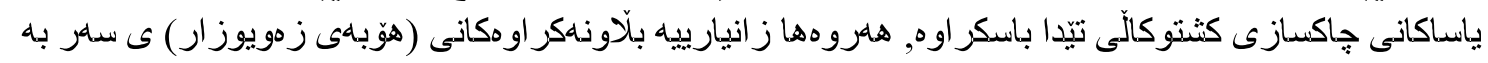

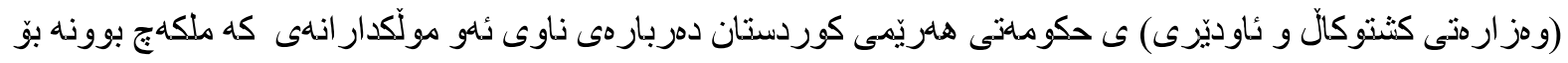

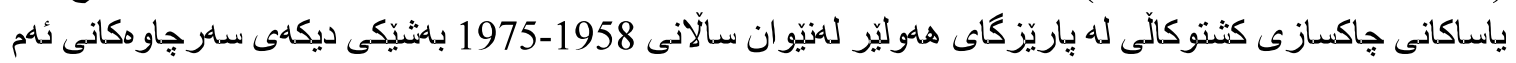

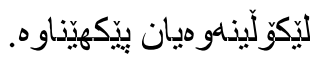

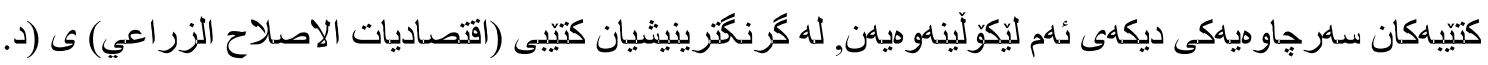

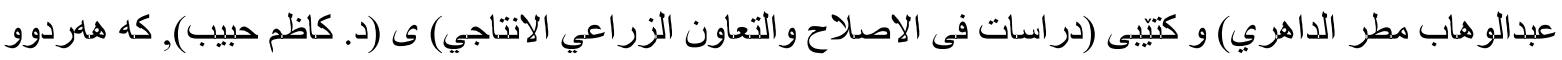

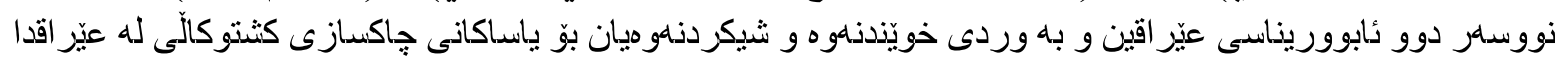

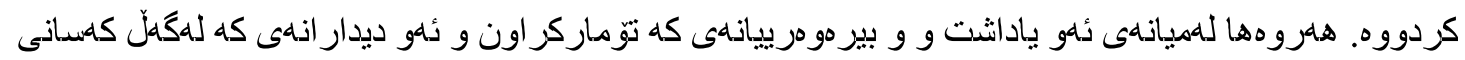

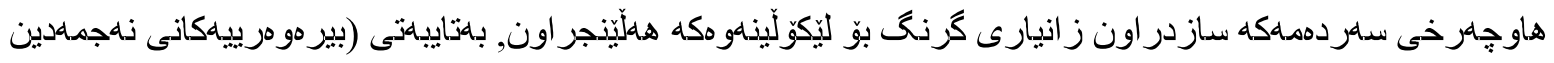

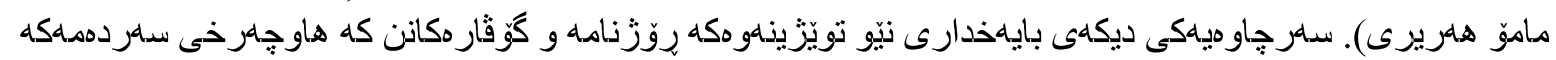

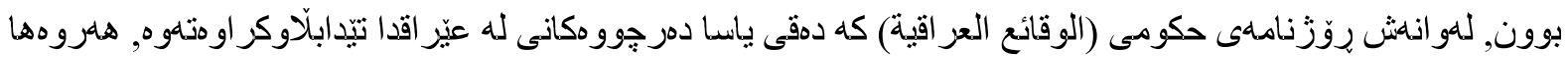

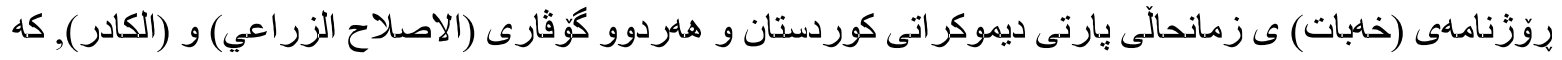

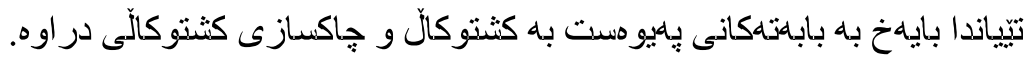
وشه كليل: ياسا, كثتوكآّ, جُاكسازى, هلوليّر, ئابوورى.

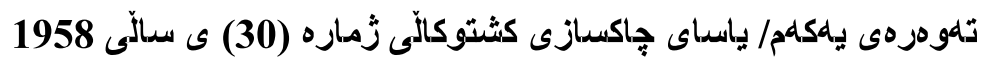




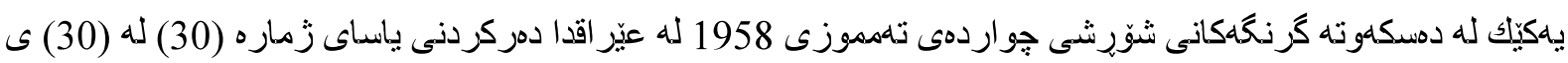

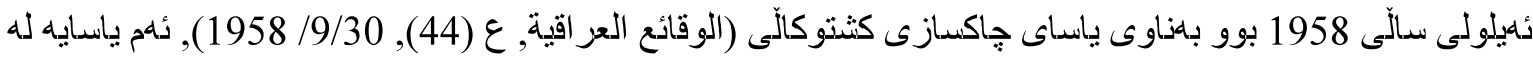

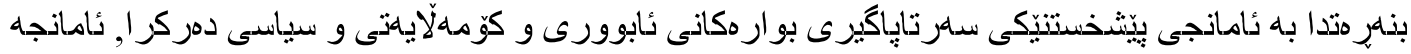

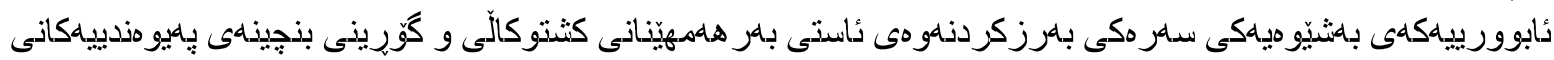

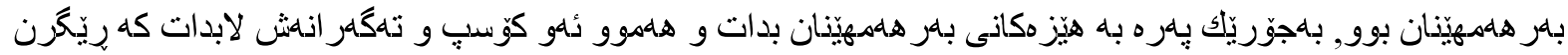

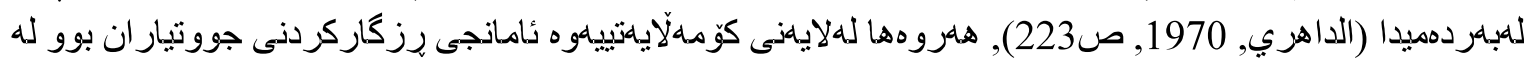

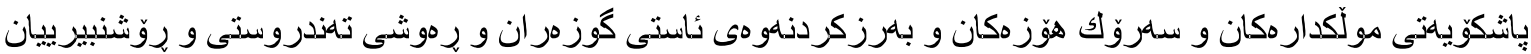

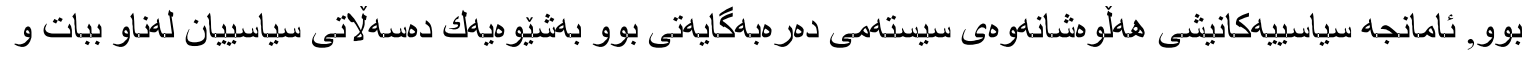

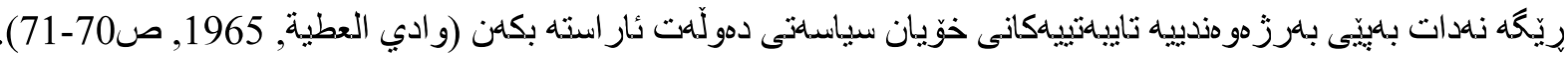

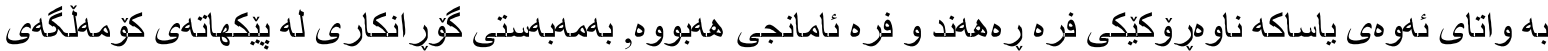
عيّر اقيدا.

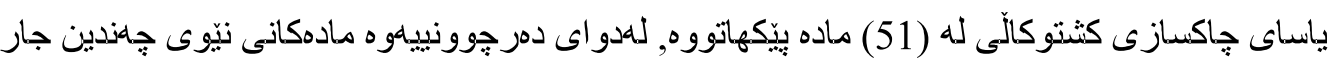

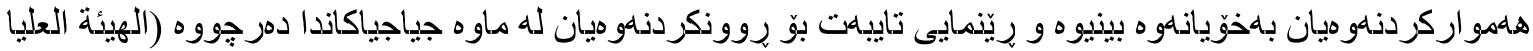

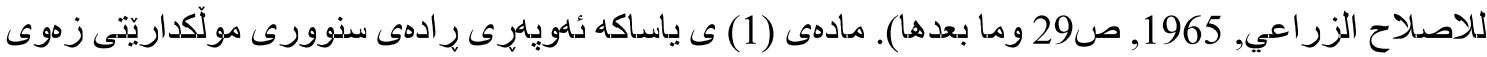

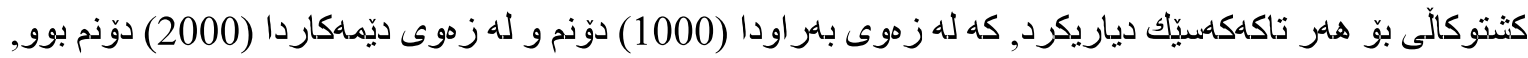

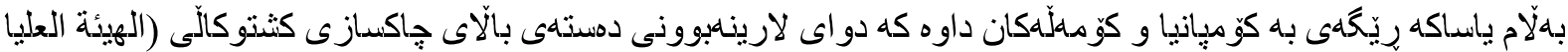

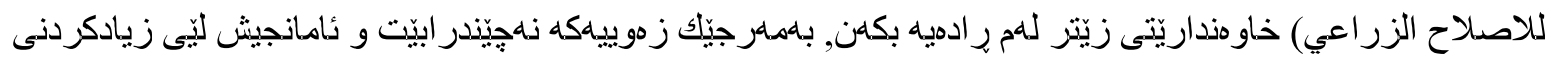

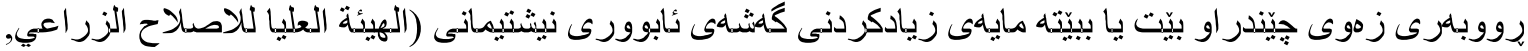

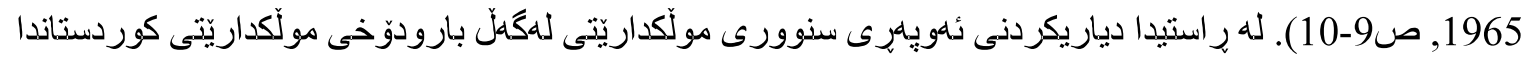

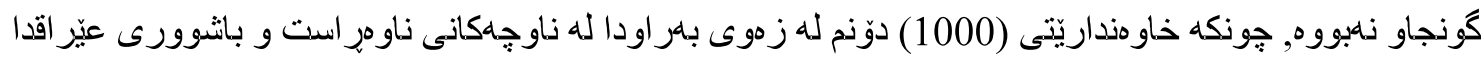

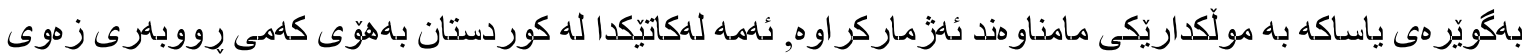

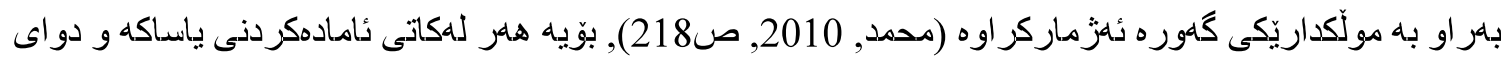

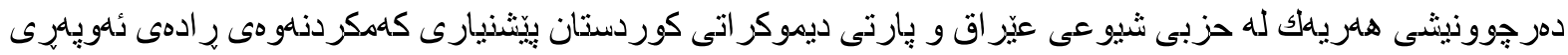

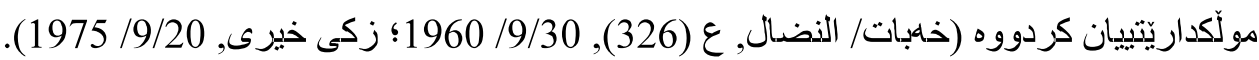

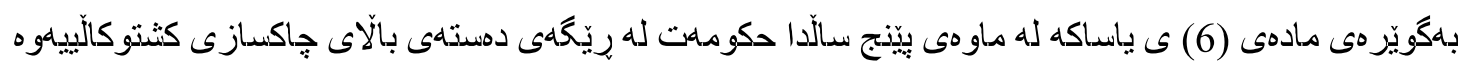

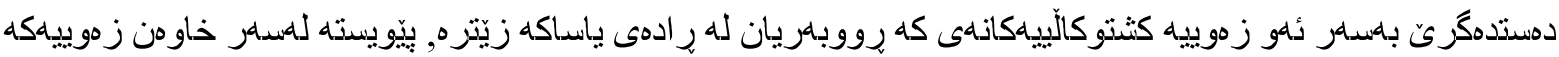

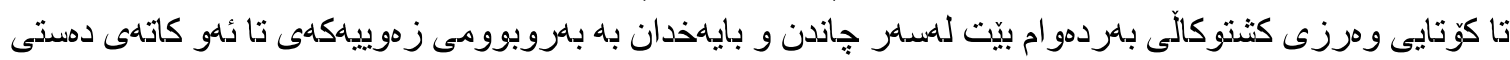

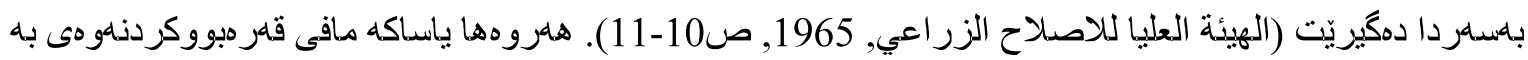

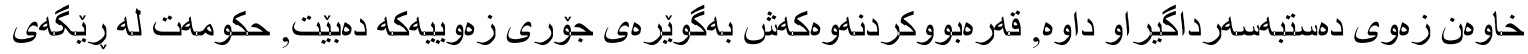

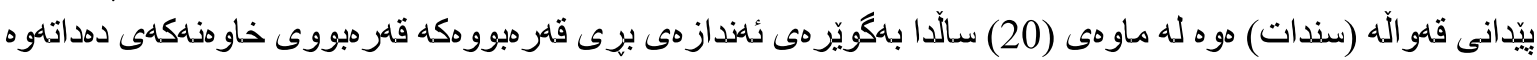

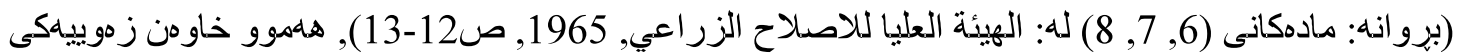

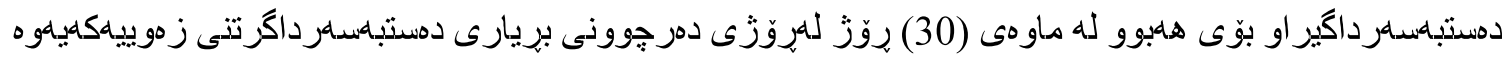

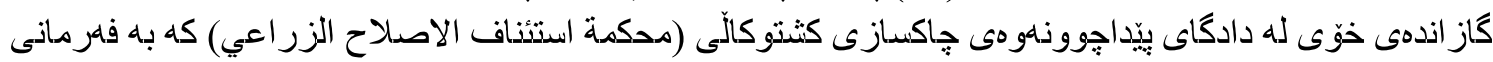

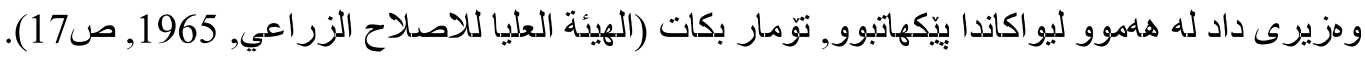

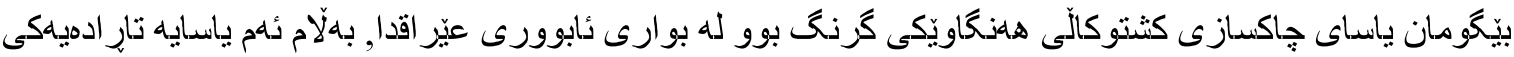

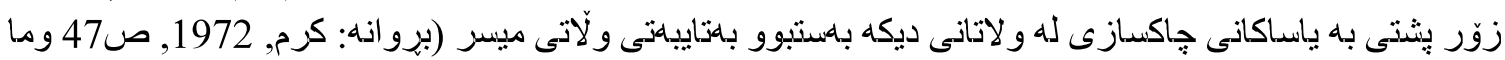

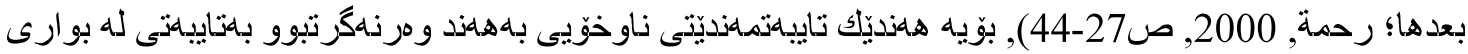

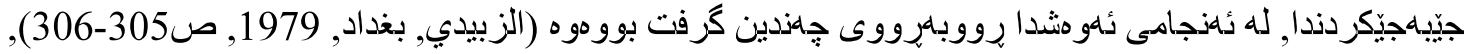

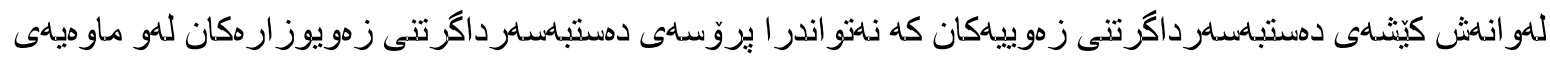

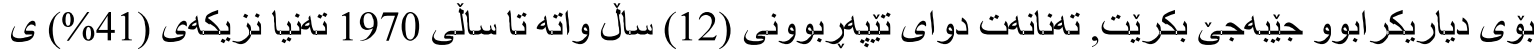

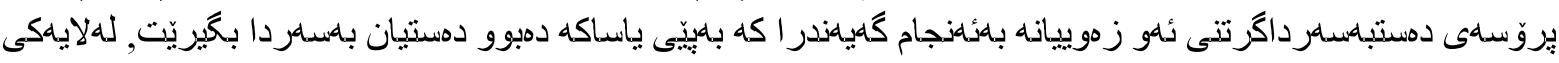




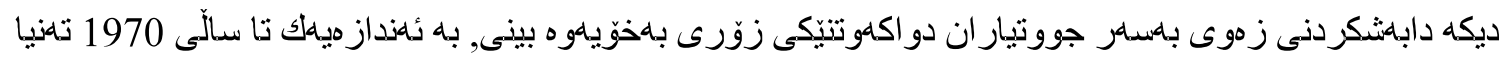

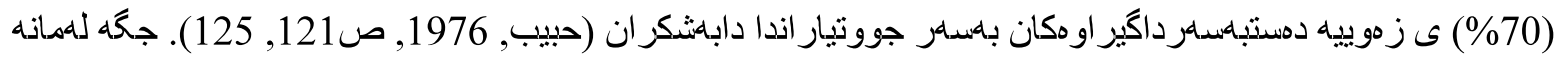

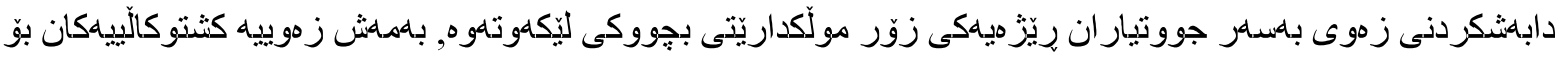

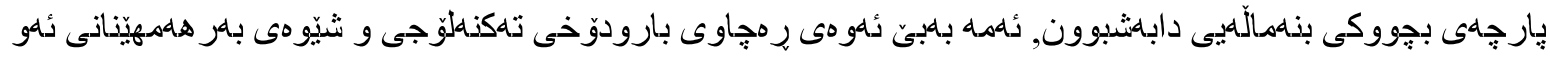

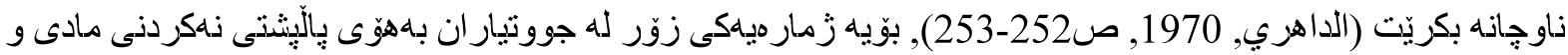

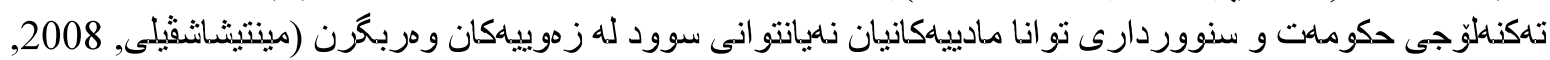

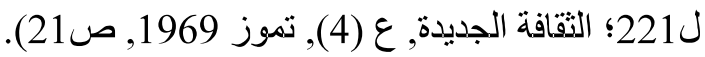

\section{1- دولّكداريّتى زهوى له هلوليّر و دهستبهسهرداكَتنى زهوييهكان}

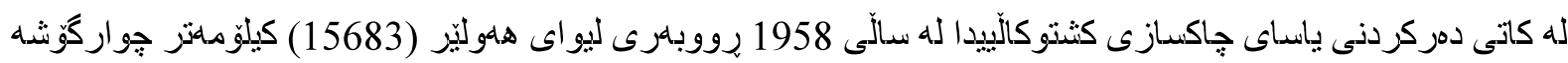

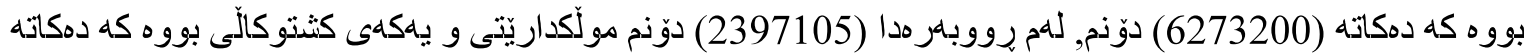
(38,2)

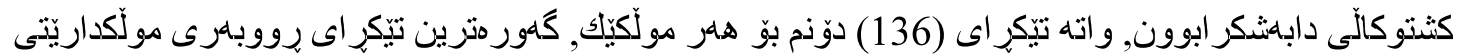

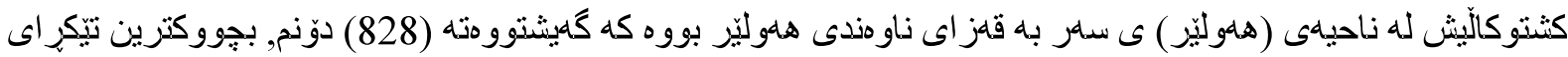

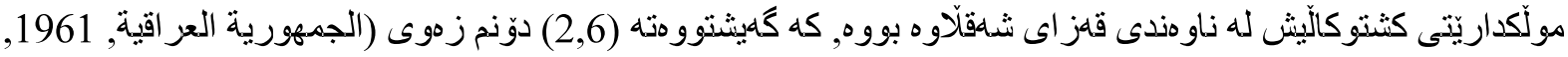

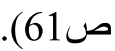

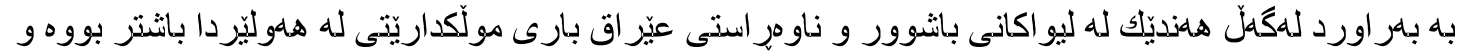

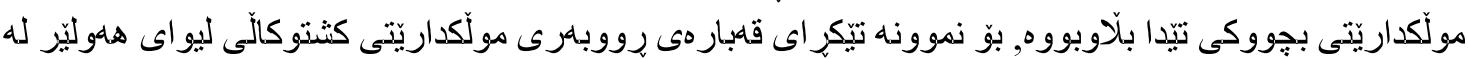

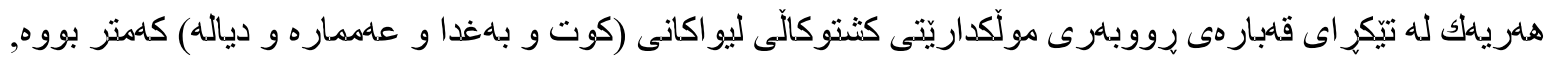

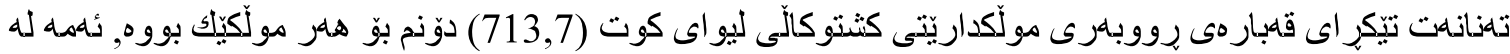

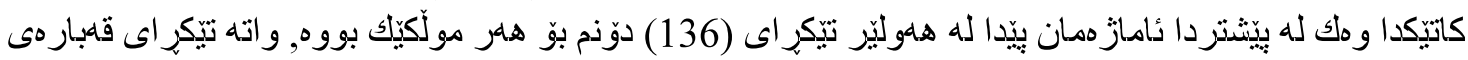

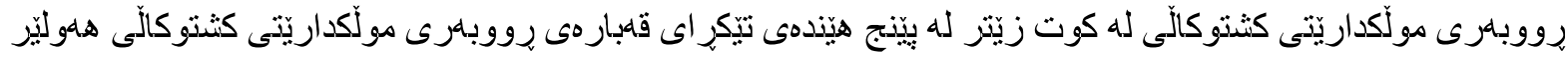

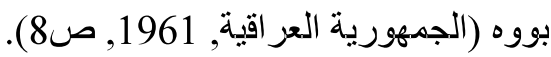

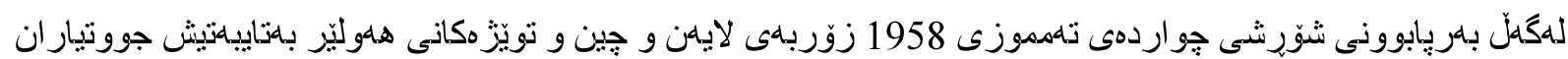

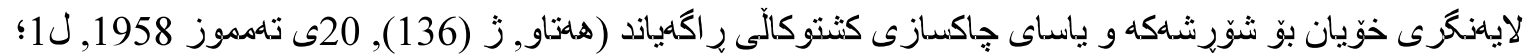

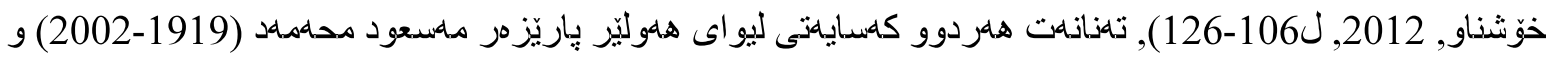

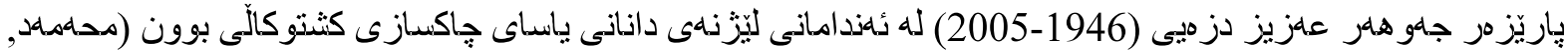

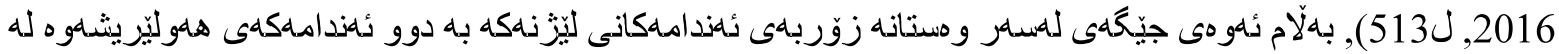

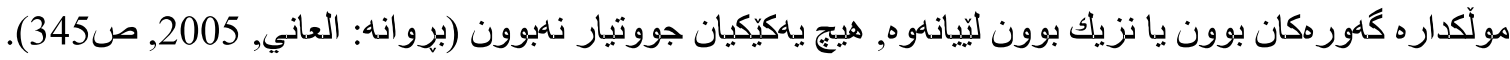

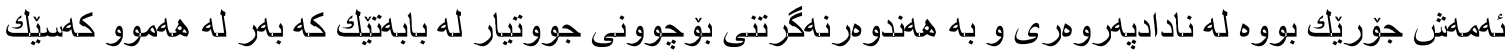

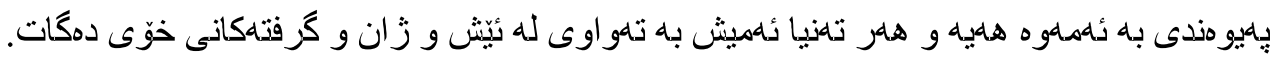

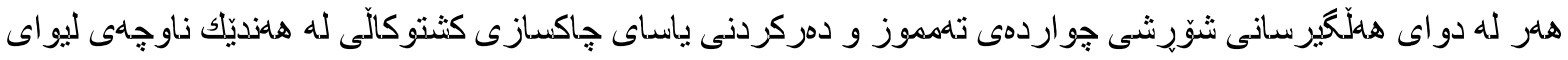

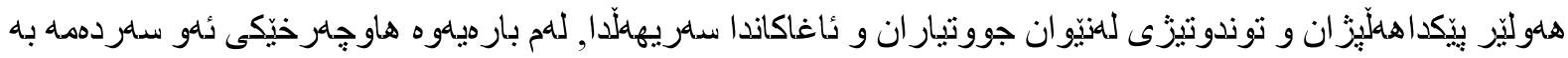

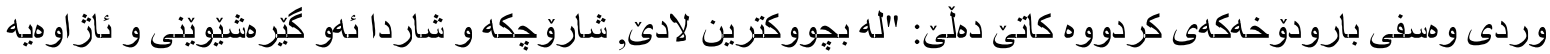

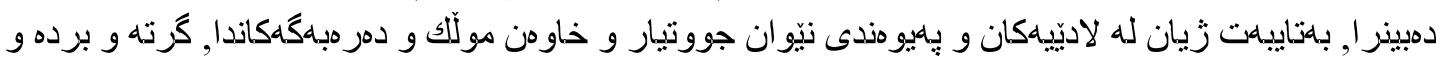

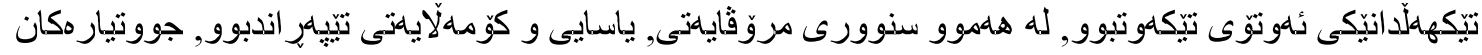

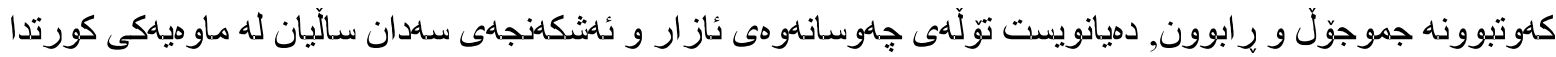

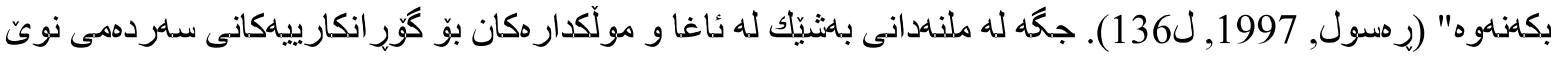

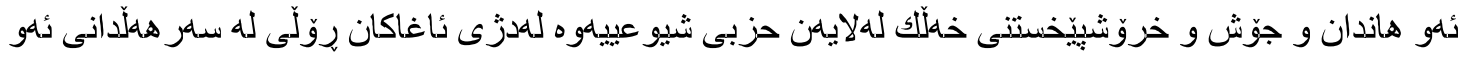




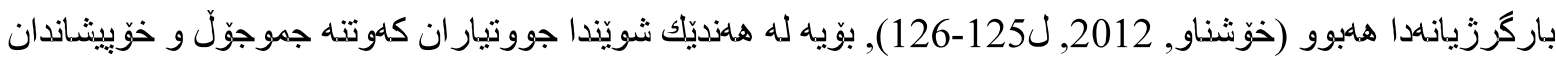

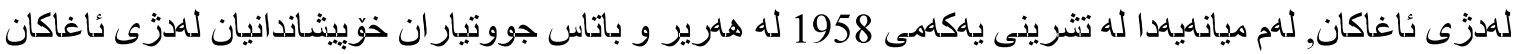

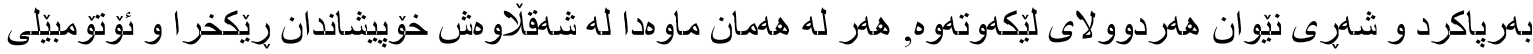

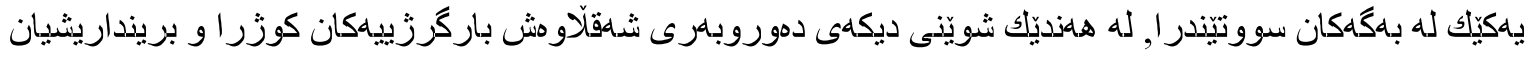

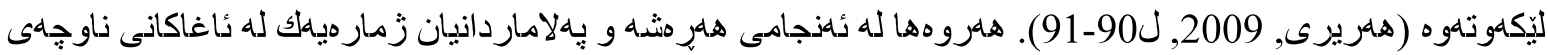

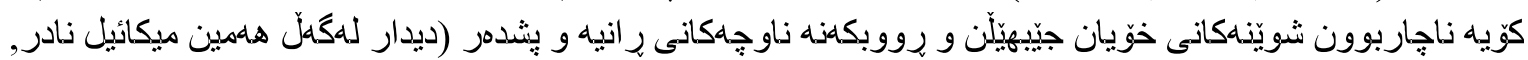

. (2017/7/26

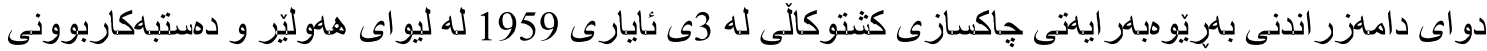

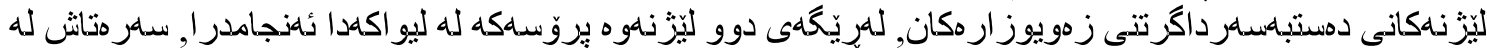

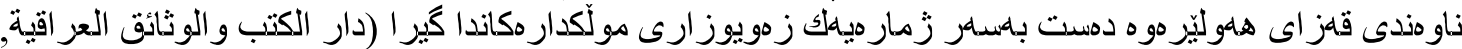

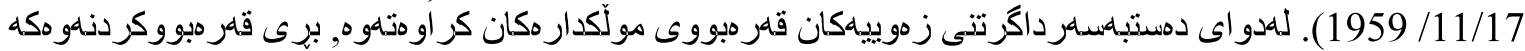

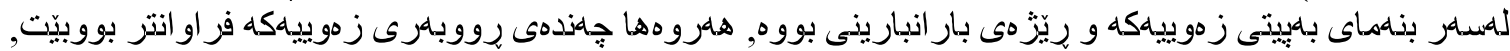

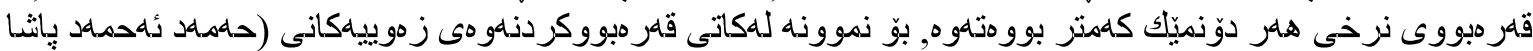

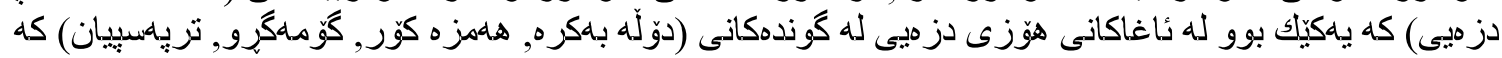

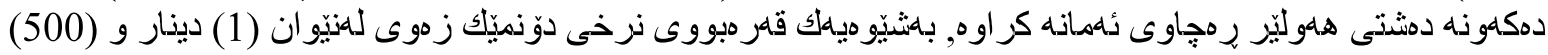

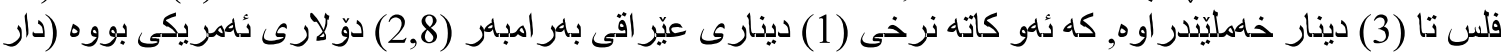

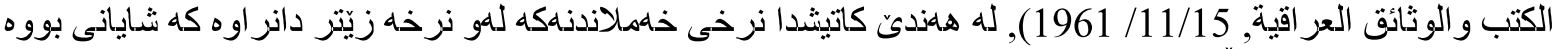

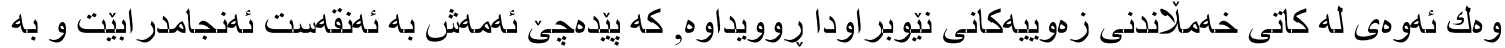

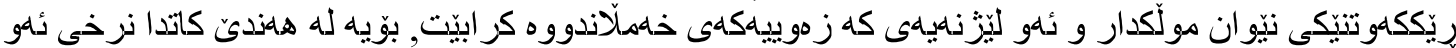

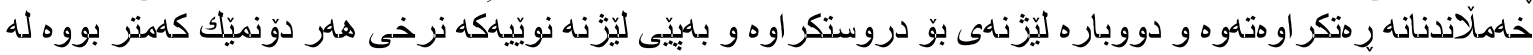

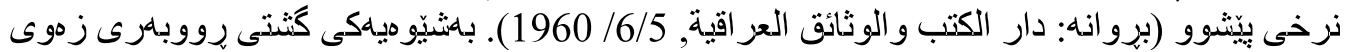

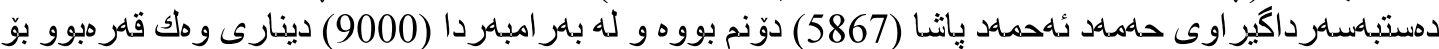

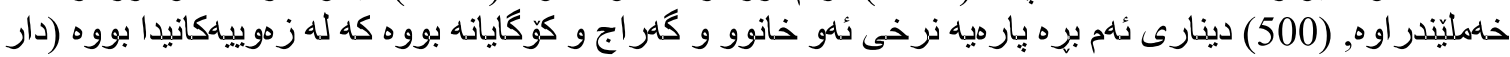

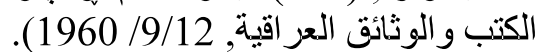

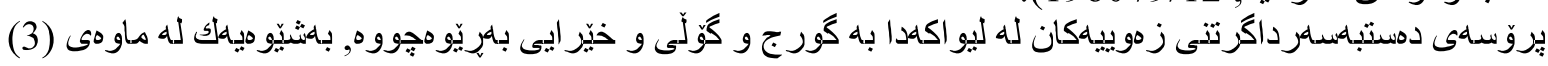

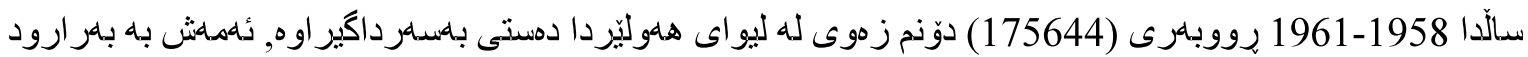

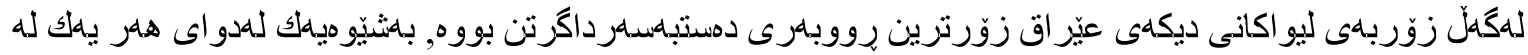

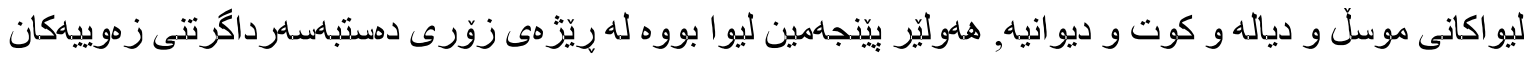

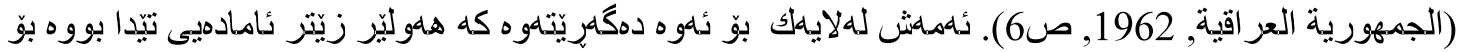

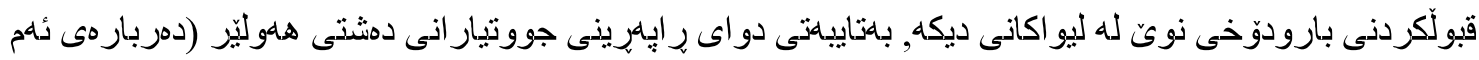

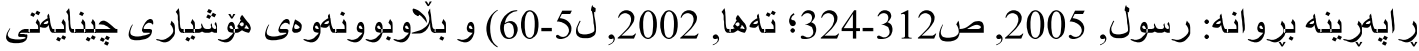

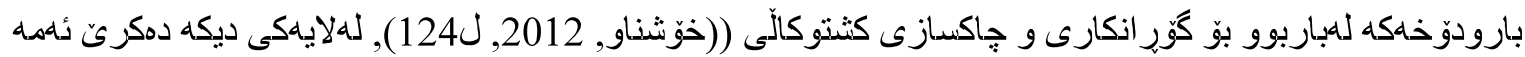

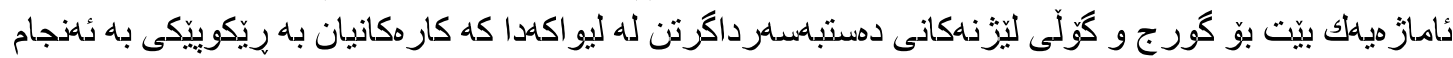

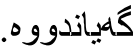

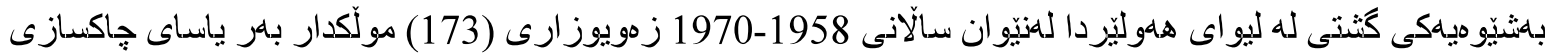

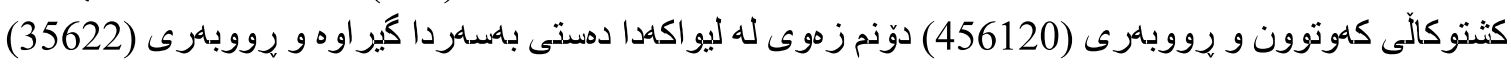

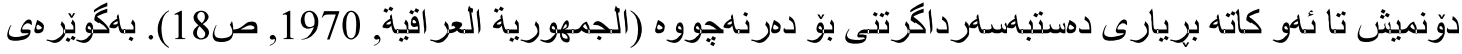

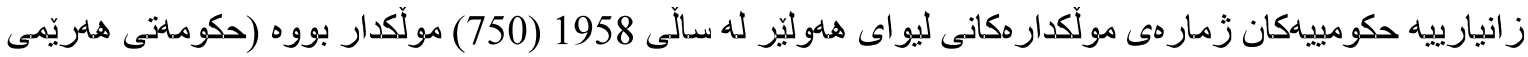

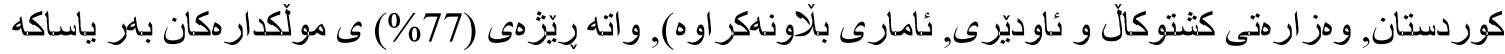

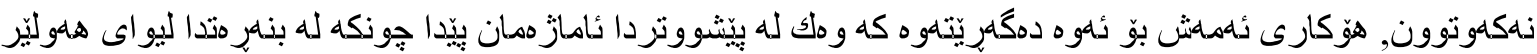

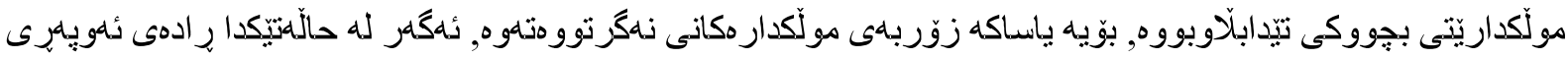

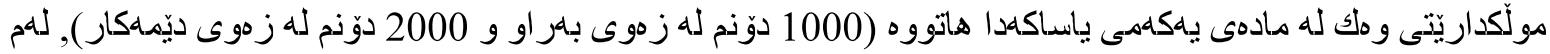

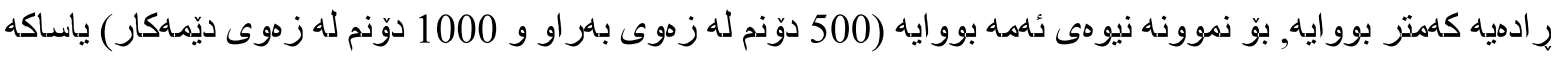


زمار ميهكى زوّرتر له مولّكدار هكانى دمكرتهوه و زمار ميهكى زياتريش له جووتيار ان له وهركزتنى زهوى سوودمهند دمبوون.

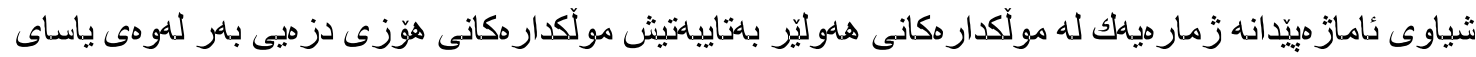

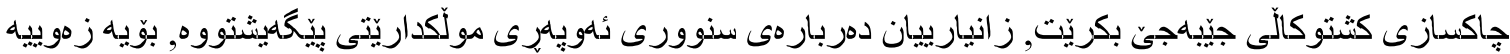

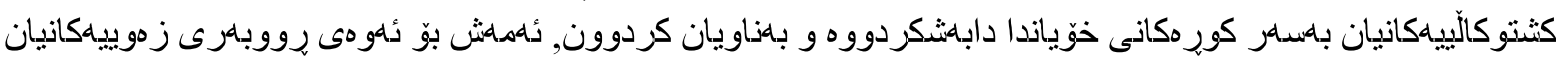

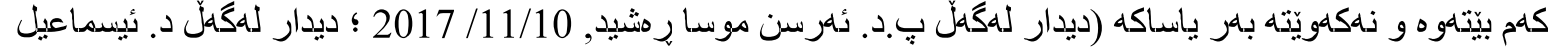

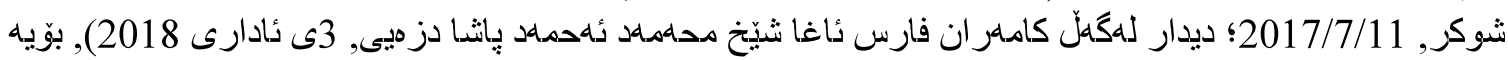

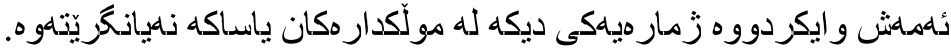

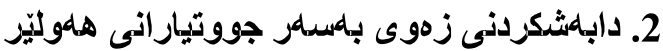

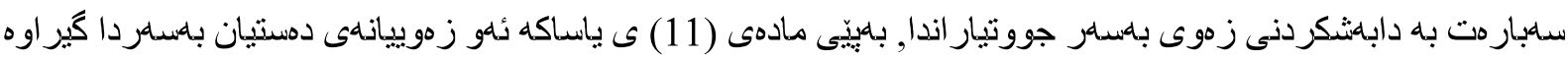

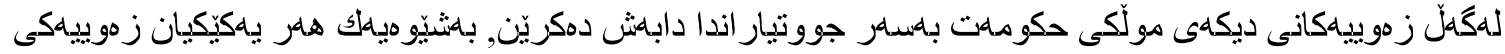

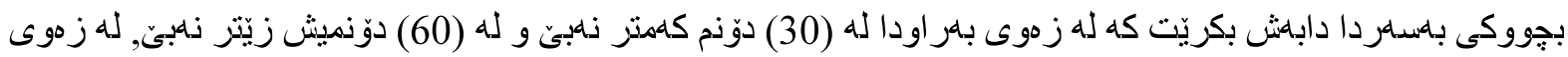

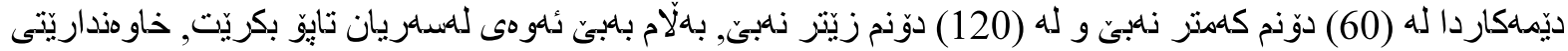

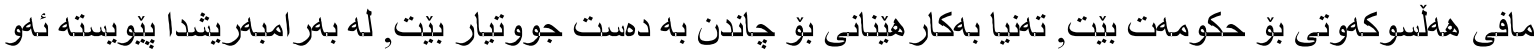

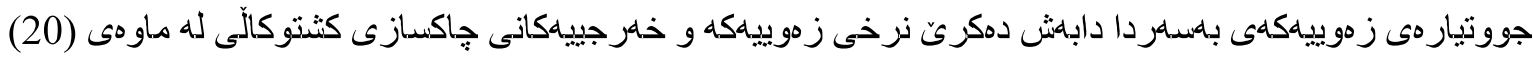

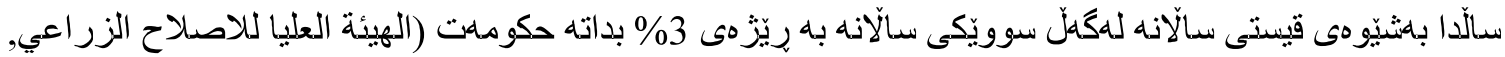
1965, ص14-14)

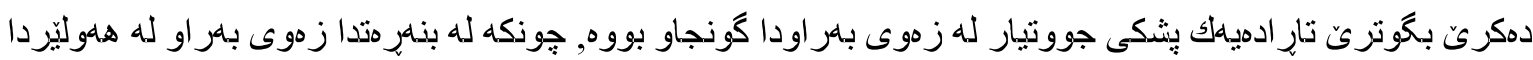

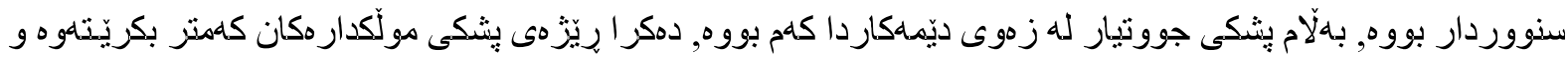

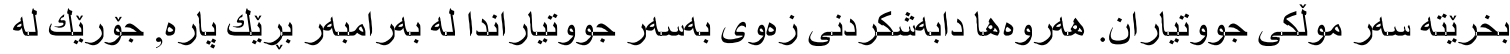

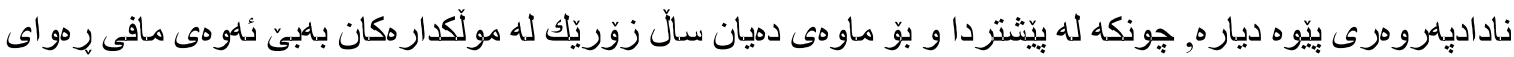

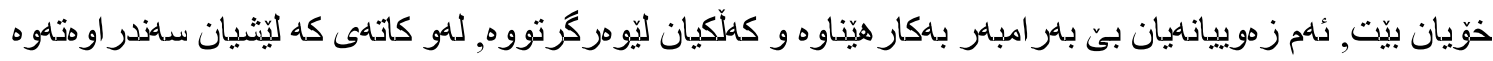

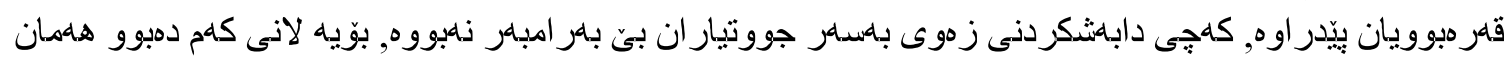

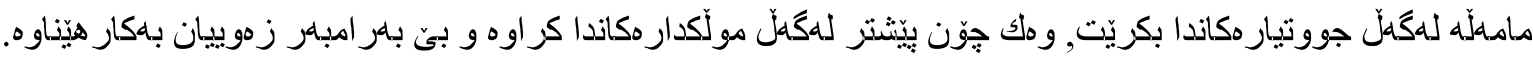

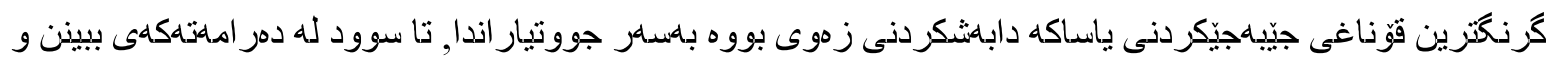

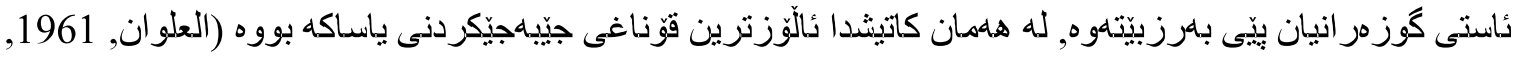

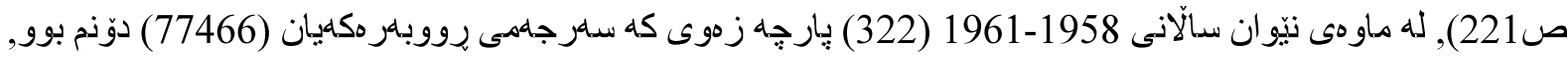

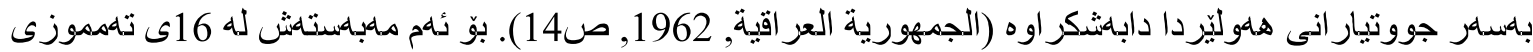

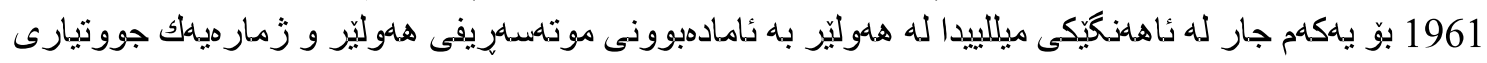

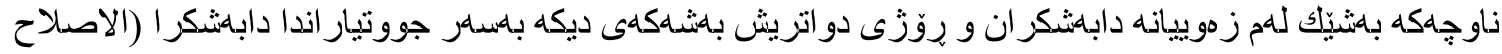

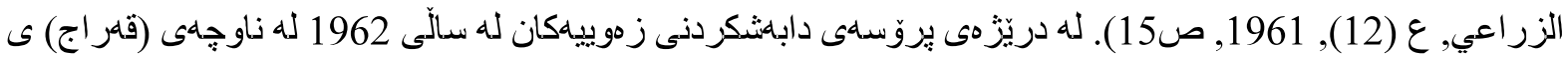

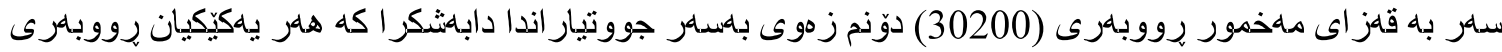

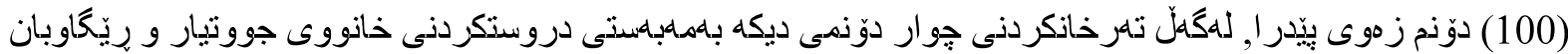

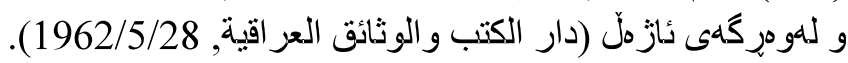

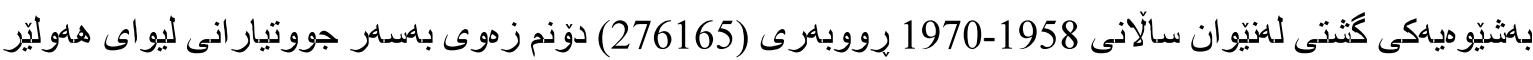

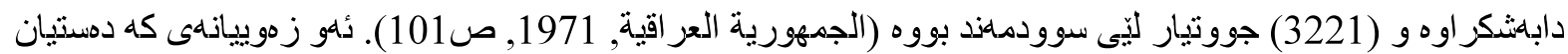

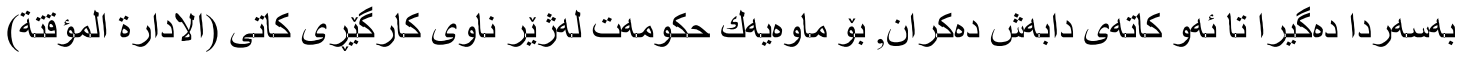

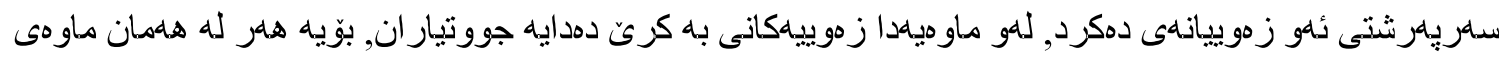




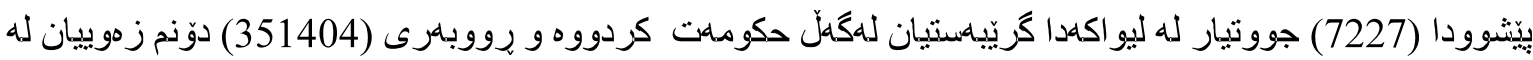

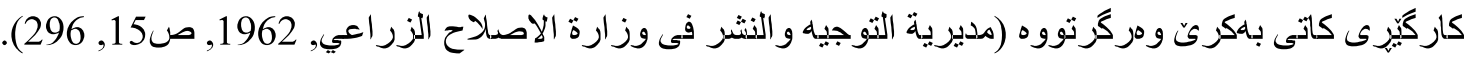

\section{3- كاريحَرى يرووداوهكانى شوّرشى ئهيلولى 1961 للسدر جيّبهجيّكردنى ياسداكه}

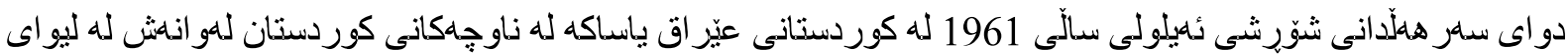

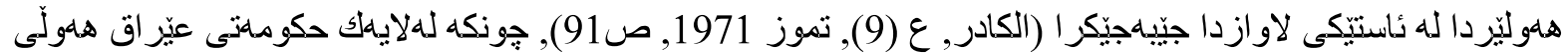

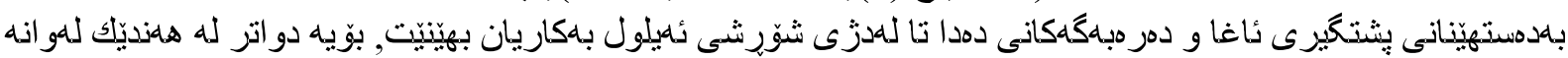

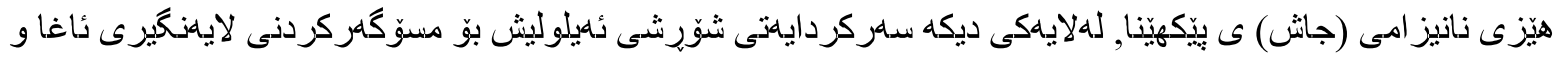

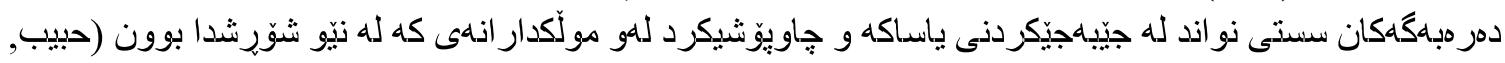

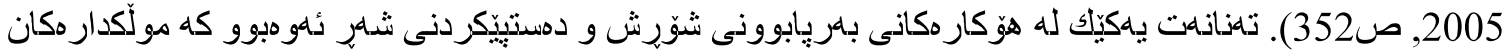

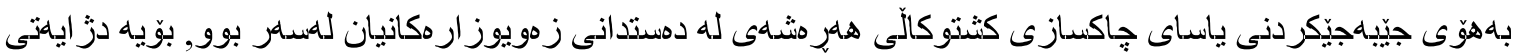

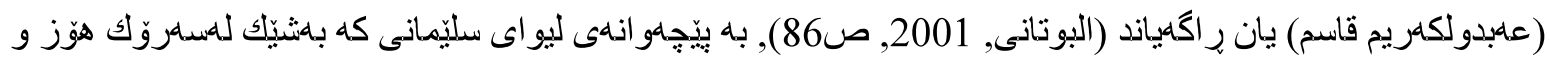

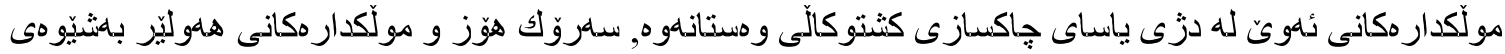

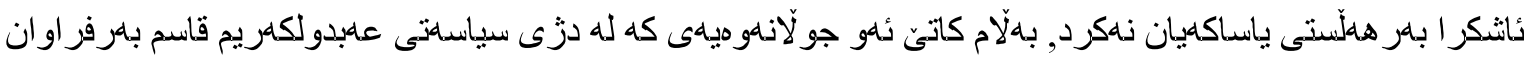

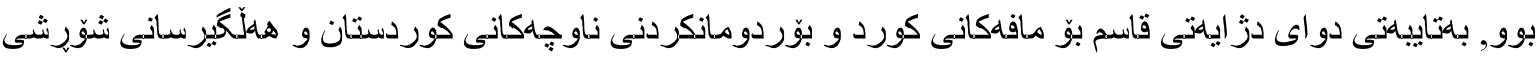

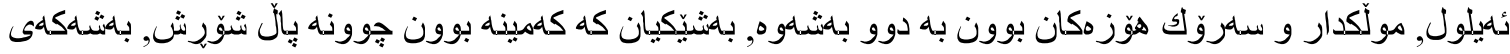

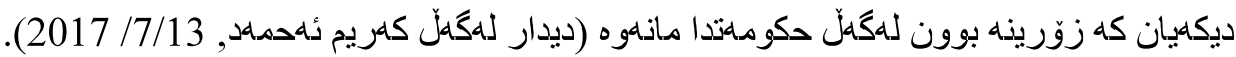

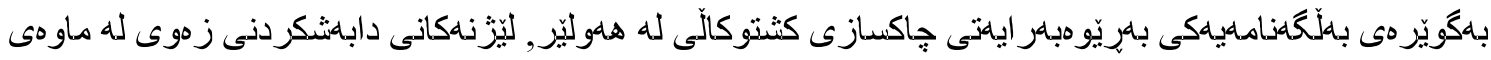

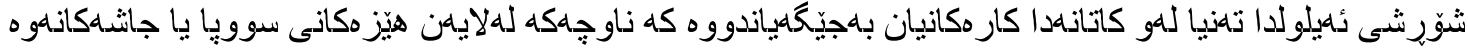

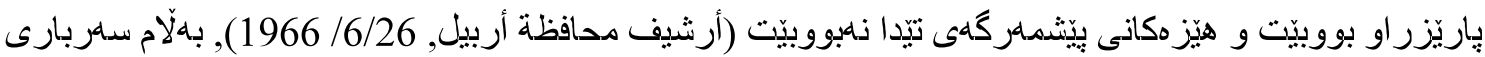

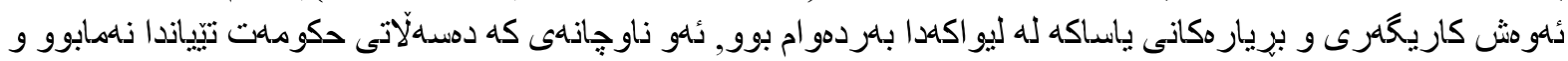

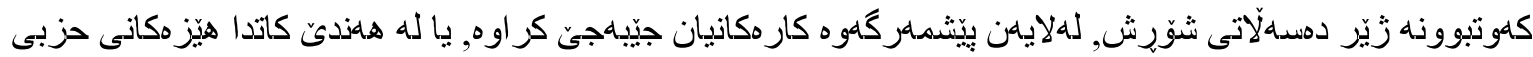

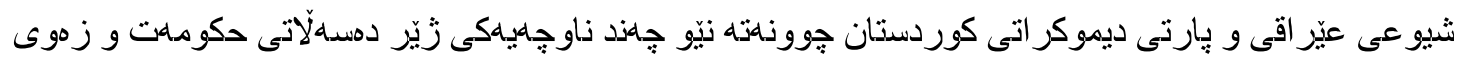

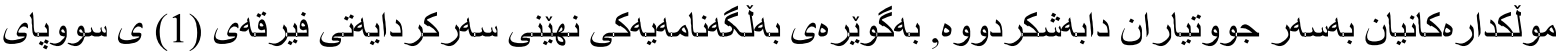

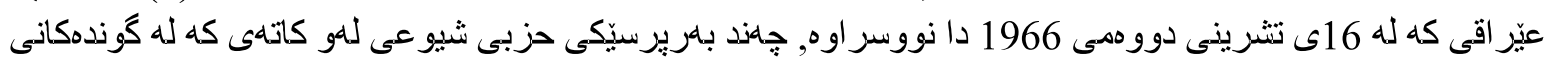

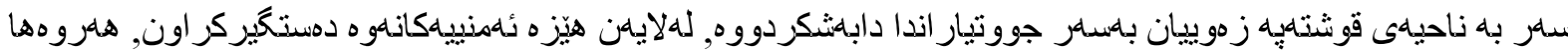

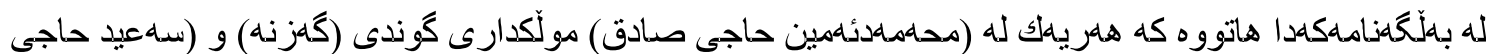

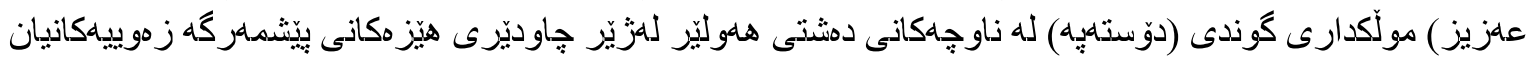

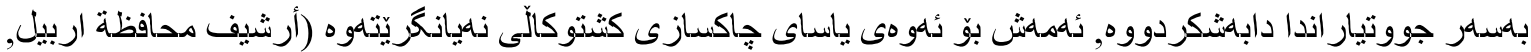

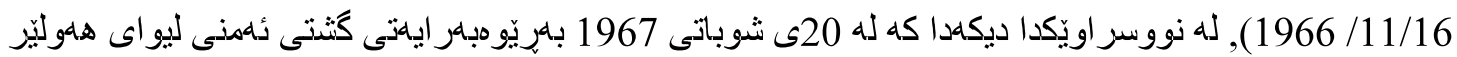

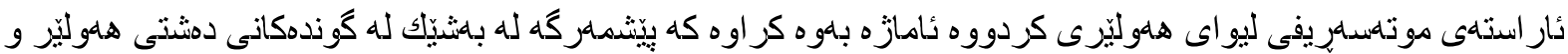

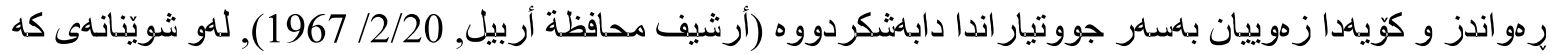

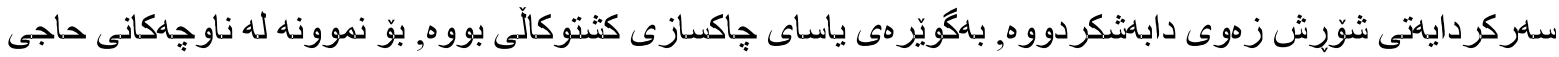

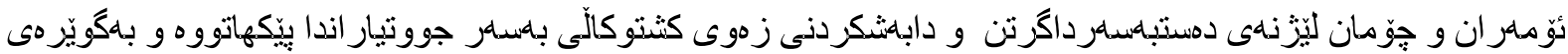

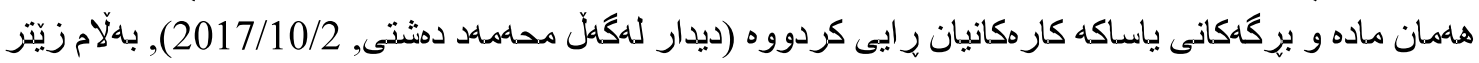

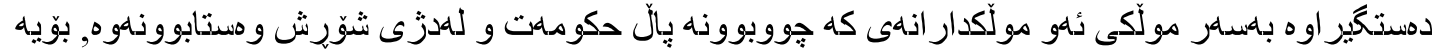

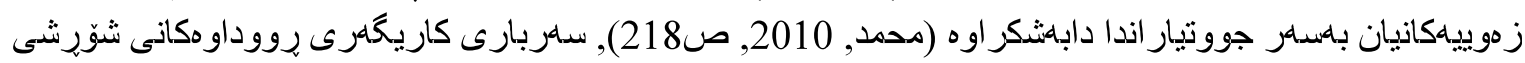

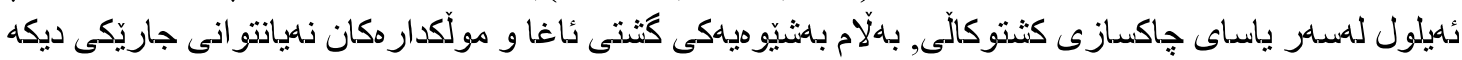

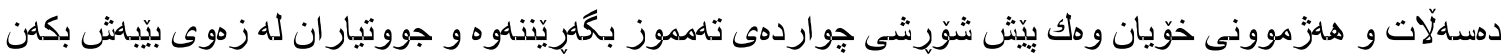

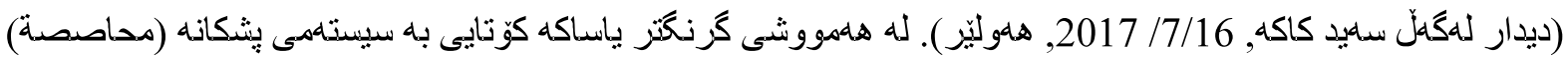

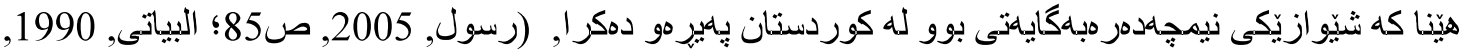

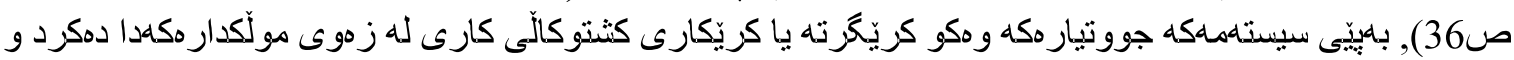




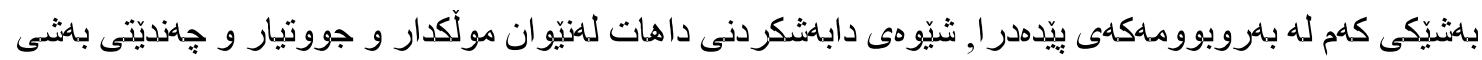

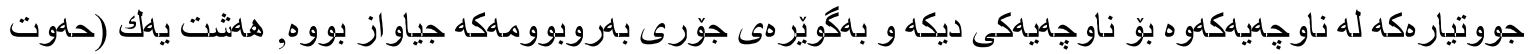

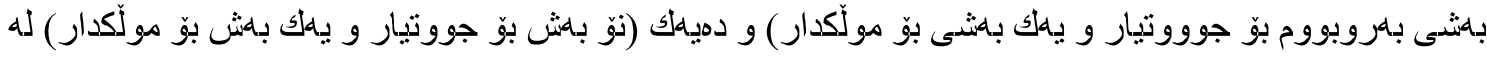

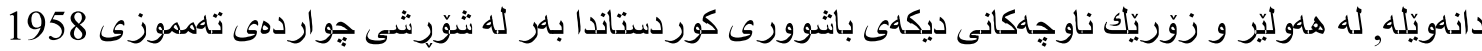

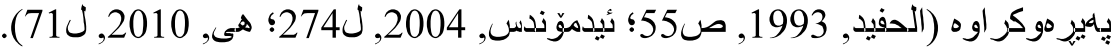

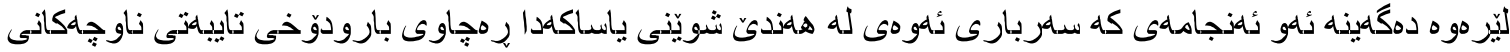

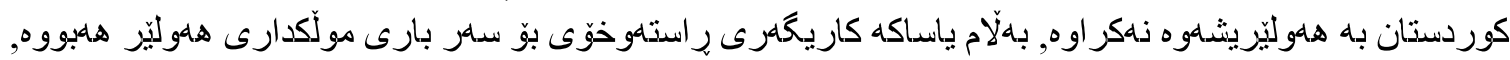

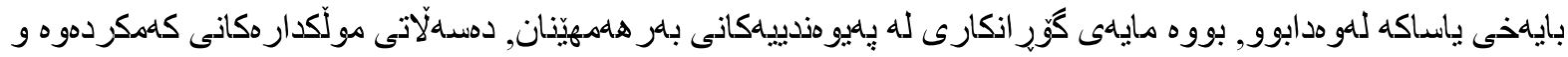

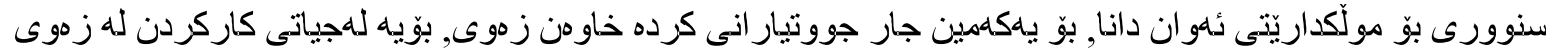

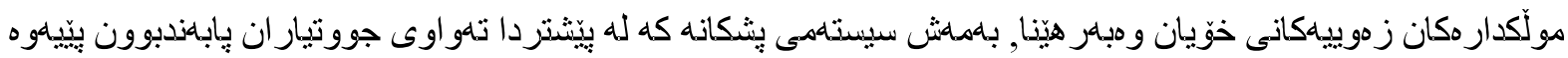

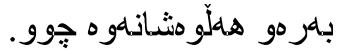

تهوهرهى دووهم/ ياساى جِاكسازى كشدّوكالّى زَماره (117) ى سدالّى 1970

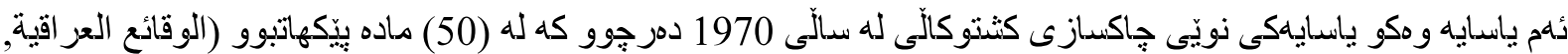

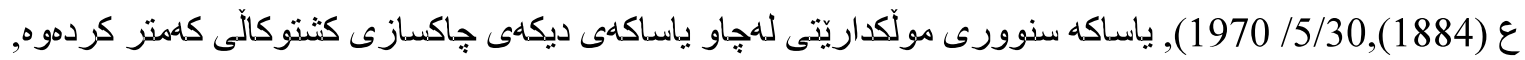

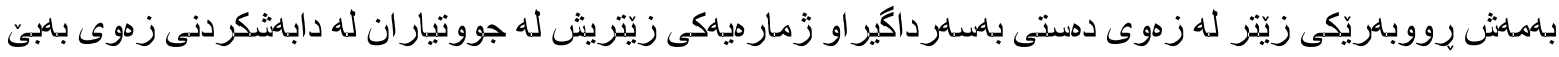

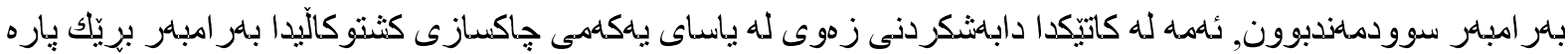

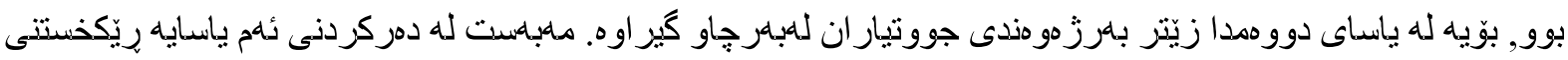

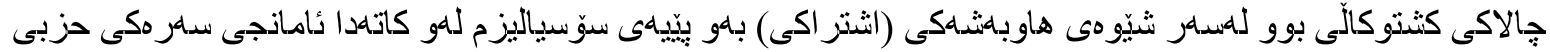

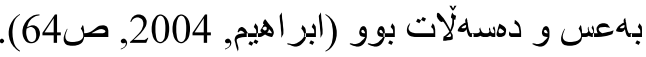

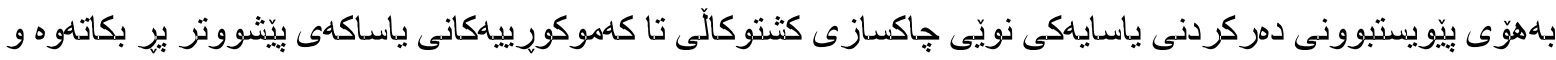

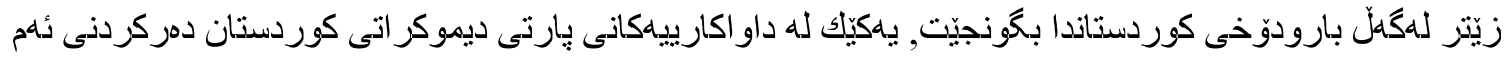

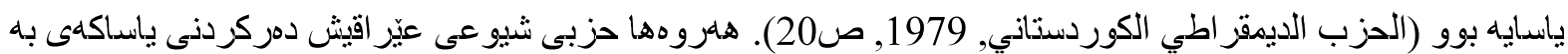

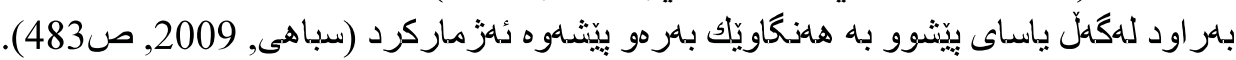

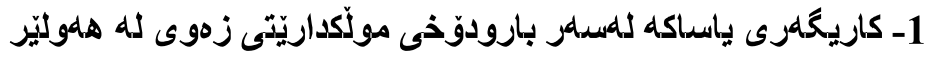

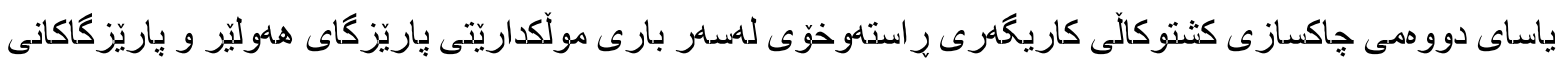

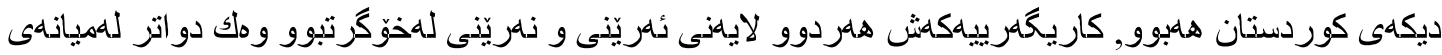

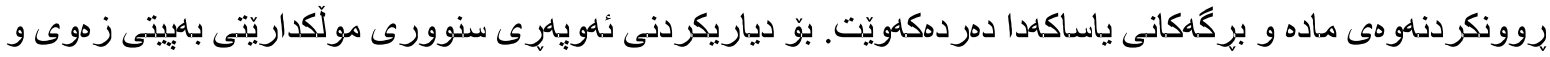

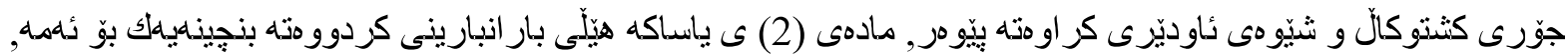

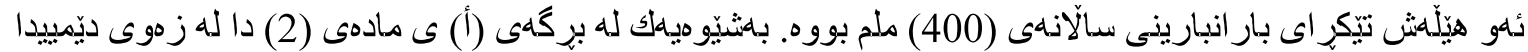

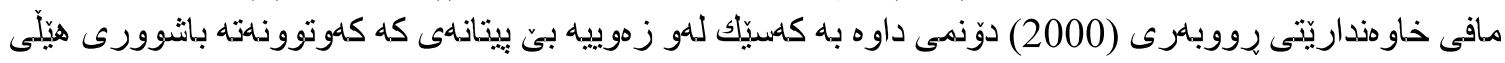

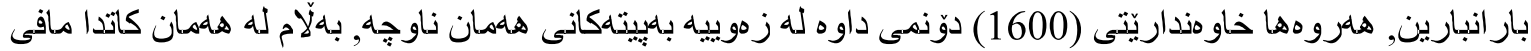

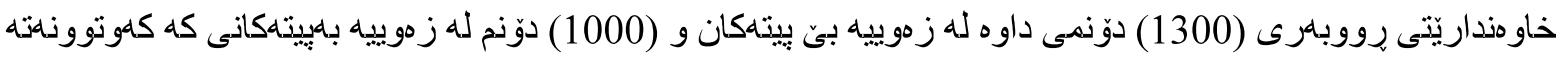

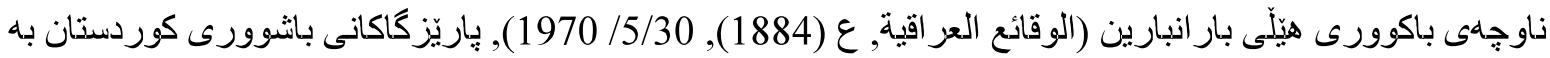

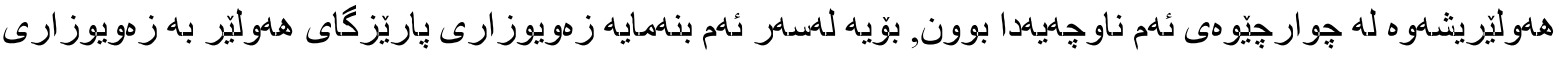

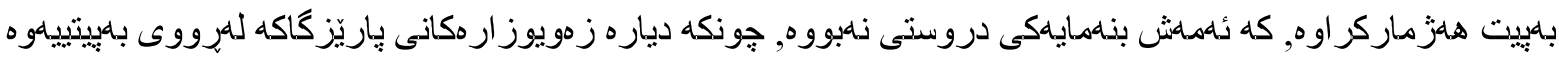

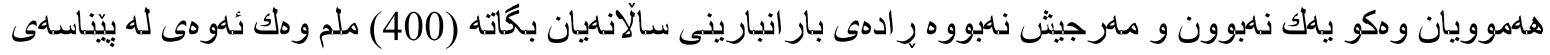

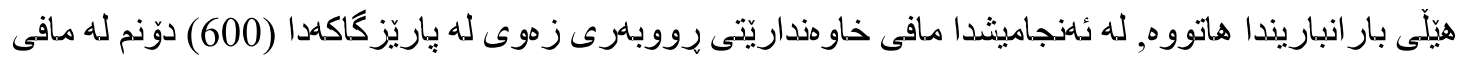

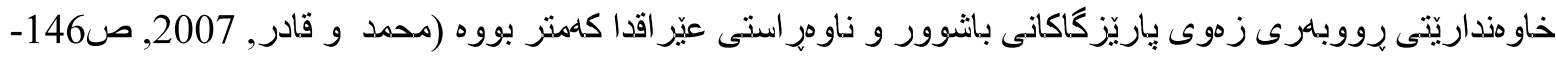

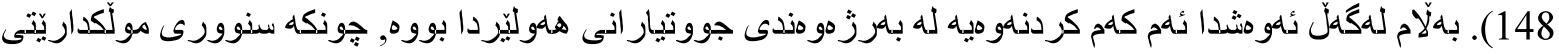




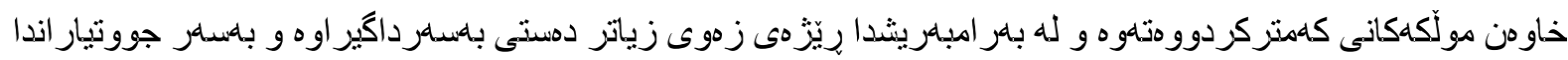
دابهنكر اوه.

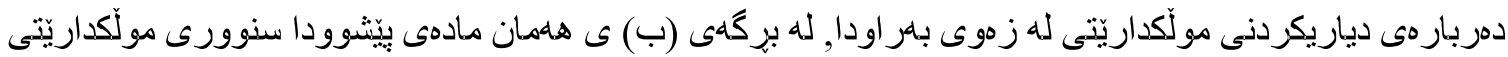

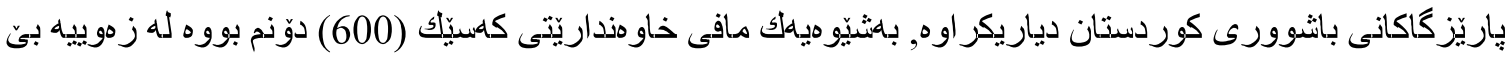

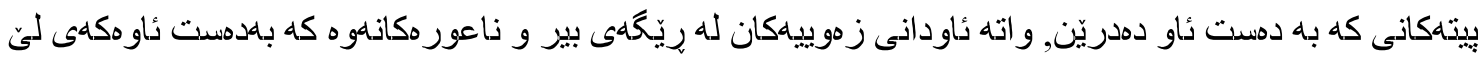

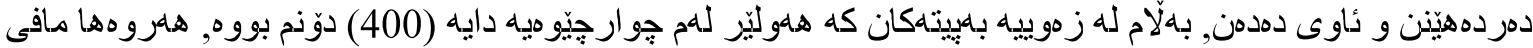

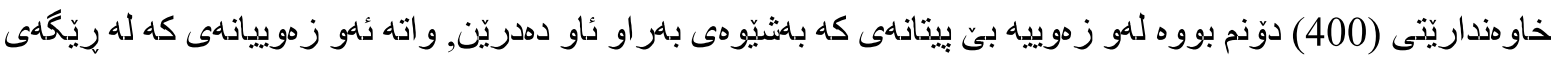

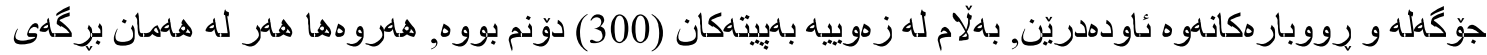

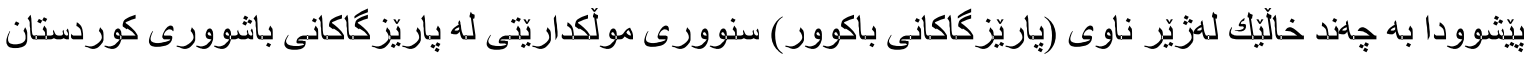

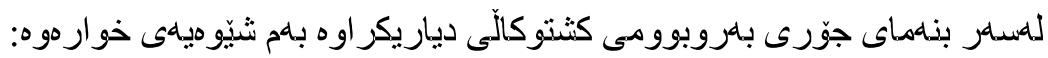
1- (120) دوّنم لهو زهوييانهى كه به دهست ئاو دهدريّن و تاييهتن به جاندنى لوّكه و سدوزه.

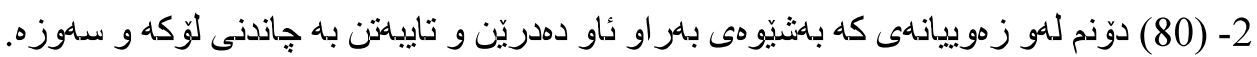
3- (80) دوّنم لهو زموييانهى كه به دهست ئاو دهدريّن و تاييهتن به جاندنى برنج. 4- (60) دوّنم للهو زموييانهى كه بهشيّومى بهر او ئاو دهدريّن و تاييهتن به جاندنى برنج. 5- (50) دوّنم للهو زموييانهى كه به دهست ئاو دددريّن و تايبهتن به جاندنى تووتن. 6- (40) دوّنم لهو زموييانهى كه بهشيّوهى بهر او ئاو دهدريّن و تاييهتن به جاندنى تووتن (الوقائع العر اقية, ع (1884), .(1970/5/30

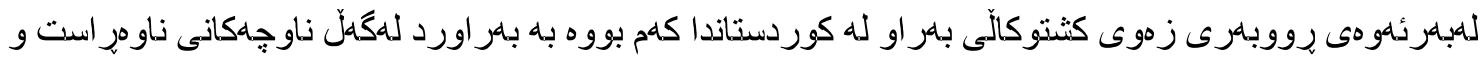

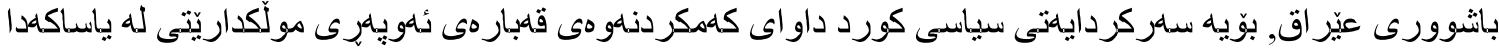

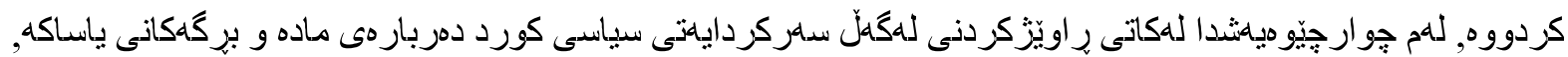

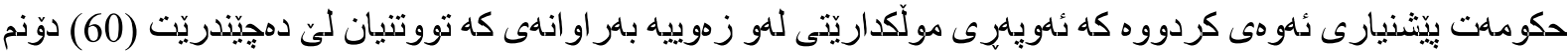

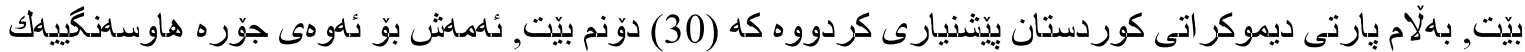

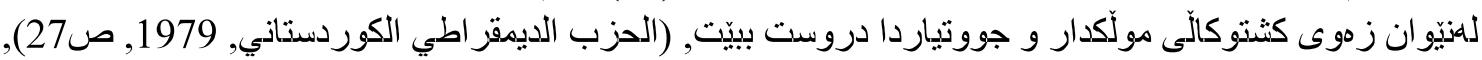

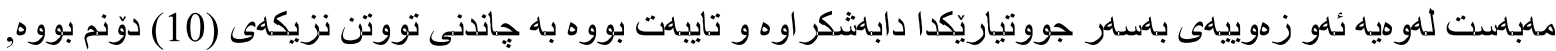

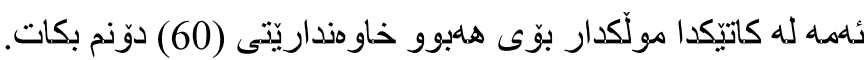

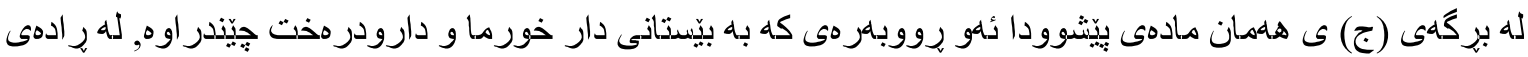

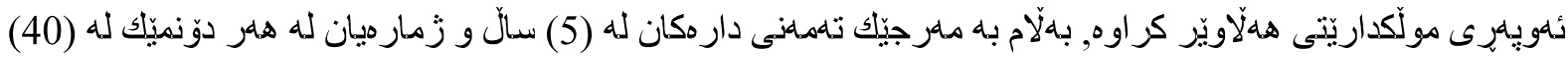

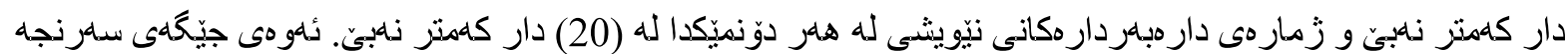

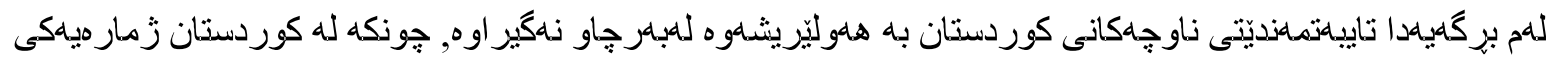

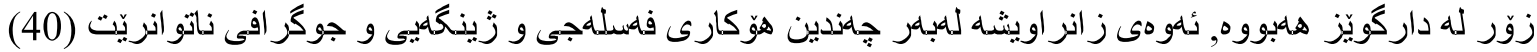

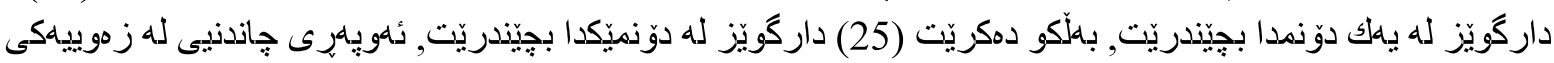

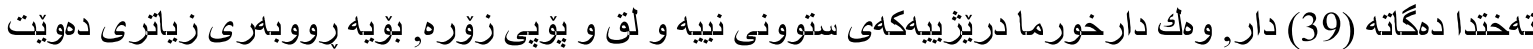

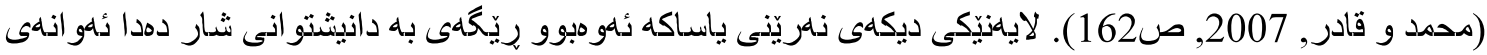

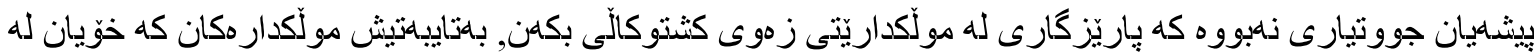

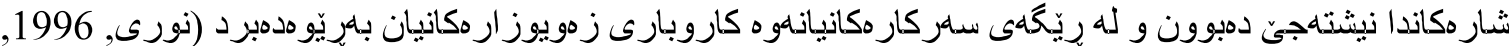
ص105). (105) 


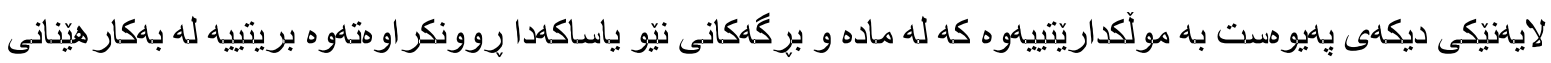

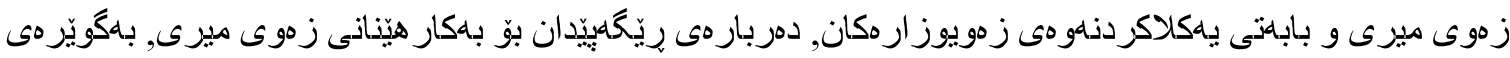

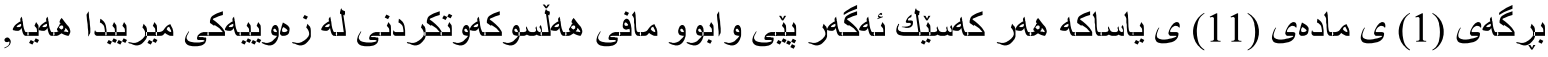

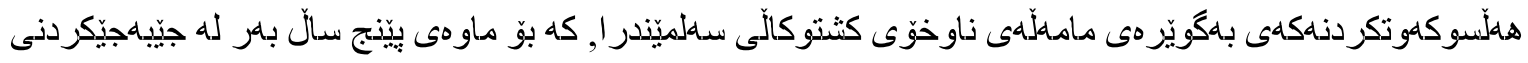

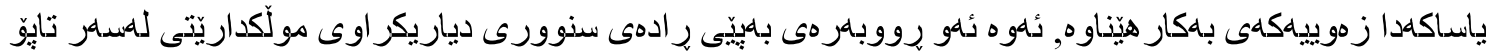

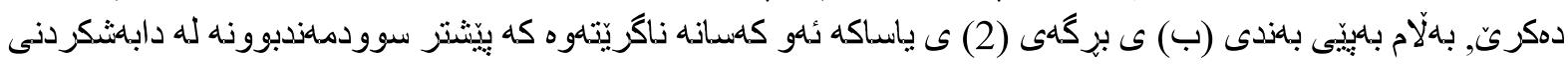

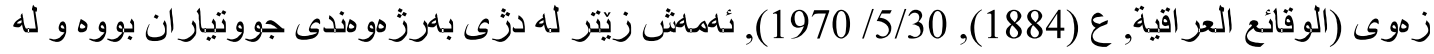

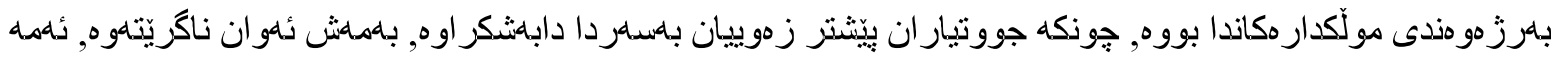

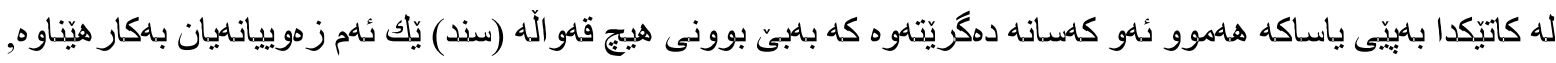
بانتاييهتيش مولَّكدار مكان.

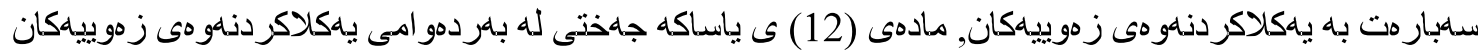

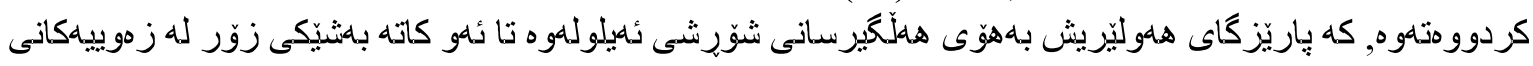

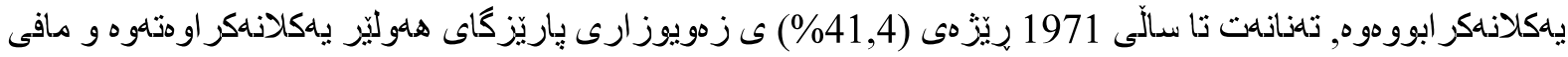

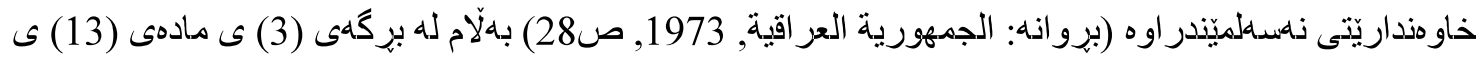

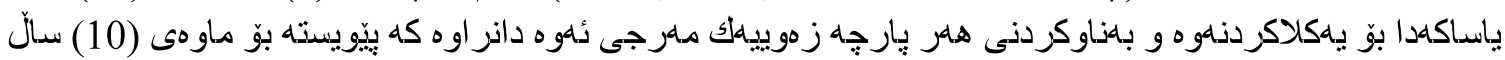

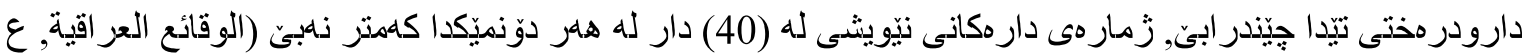

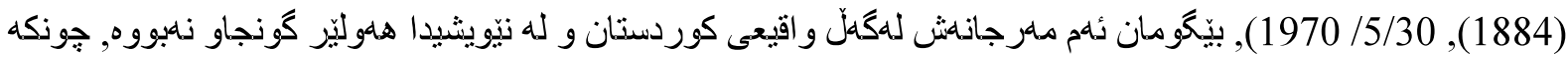

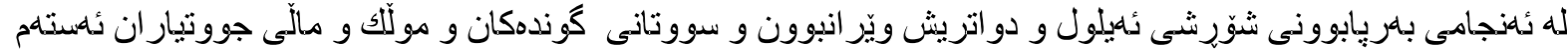

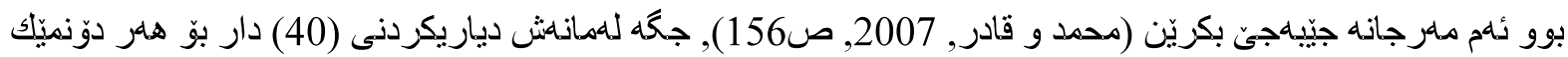

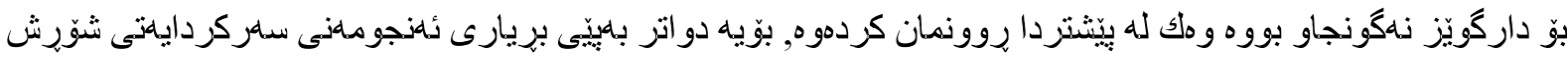

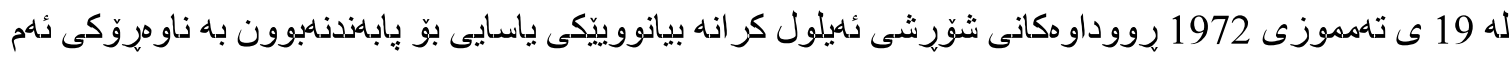

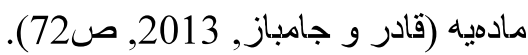

2- دهستبلسدرداكزتنى زهويوزارهكان و دابهشكردنى بلسهدر جووتياران

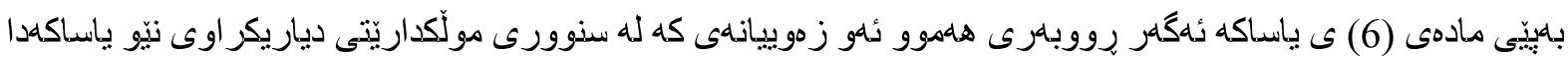

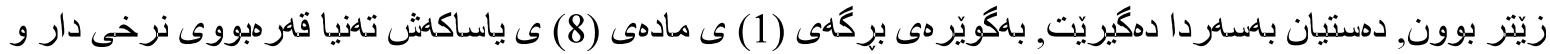

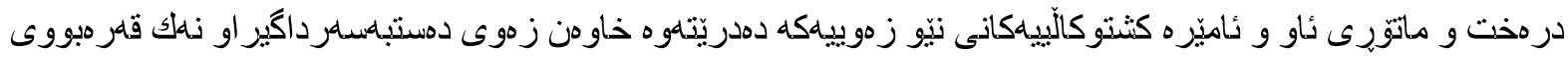

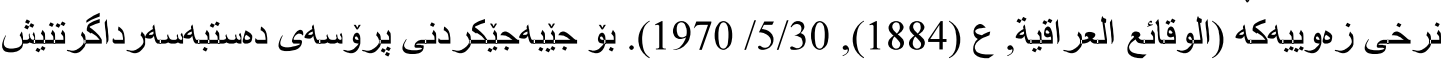

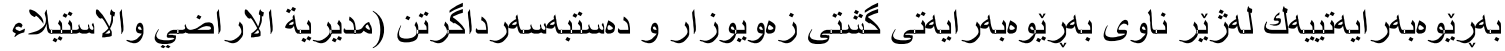

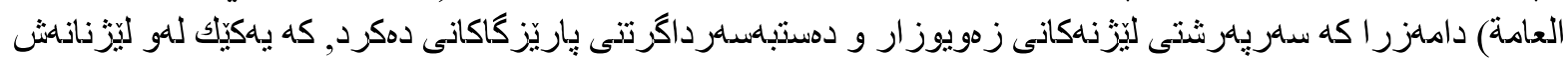

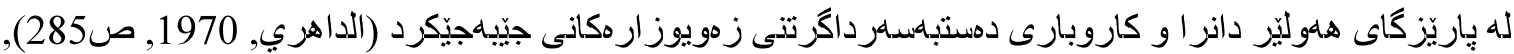

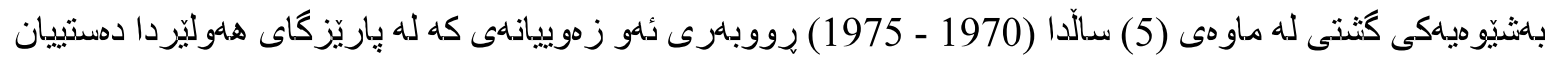

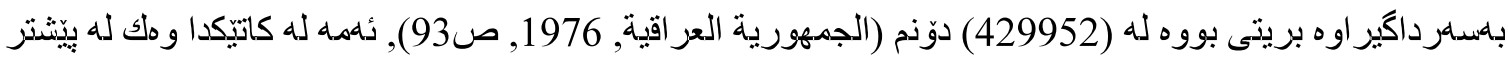

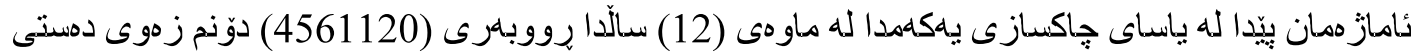

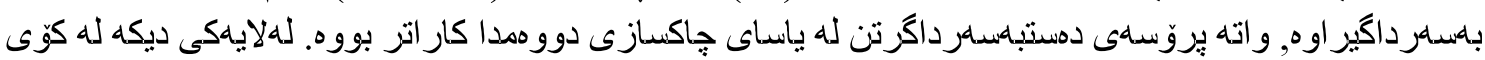

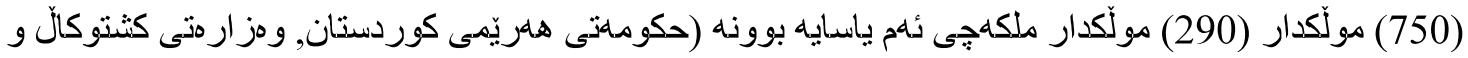

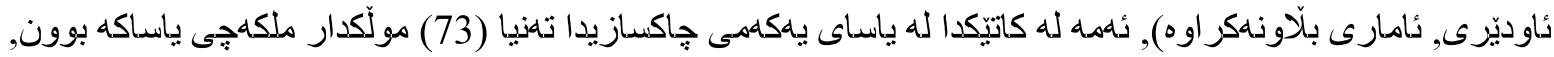

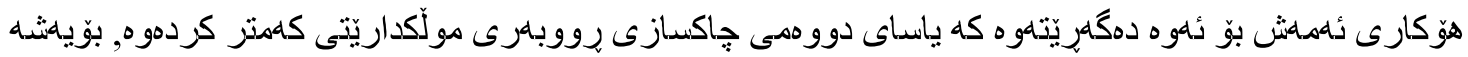

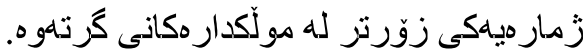




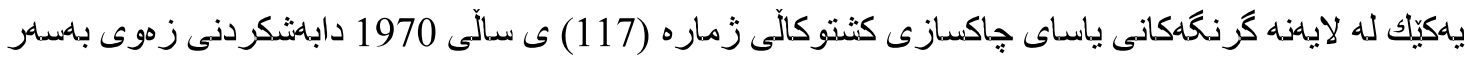

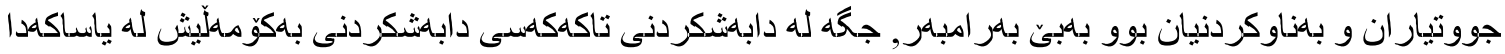

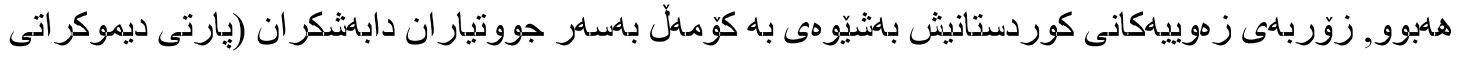

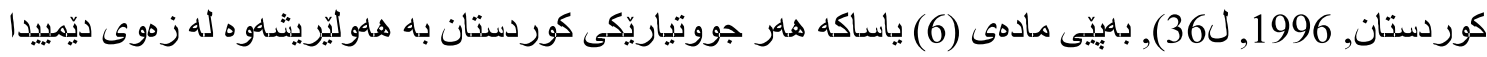

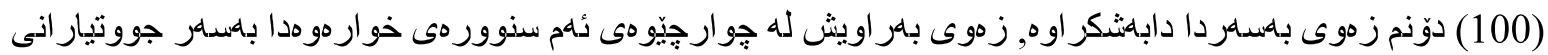

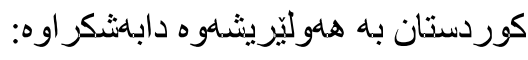

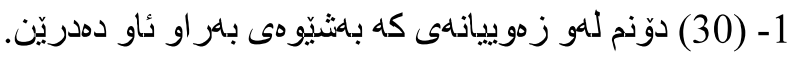

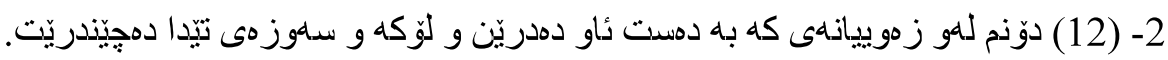
3- (8) دوّنم للهو زهو ييانهى كه بهشيْيوهى بهر او ئاو دهدريّن و (6) دوّنم لهو زهوييانهى كه به دهست ئاو دهدريّن و برنجيان تيّدا دمجِيَندريّت.

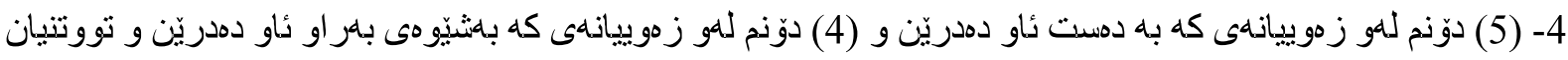

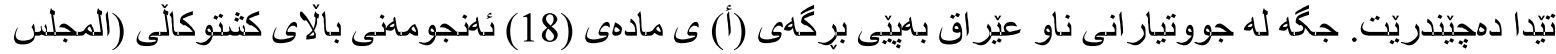

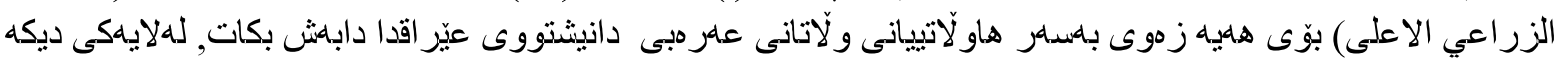

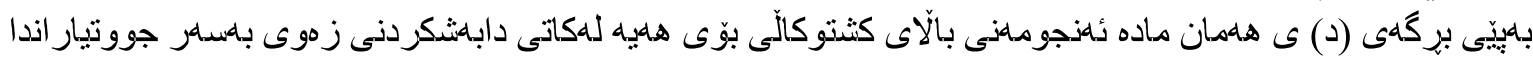

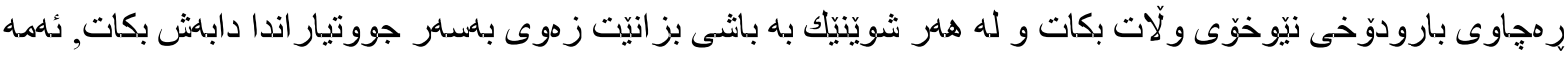

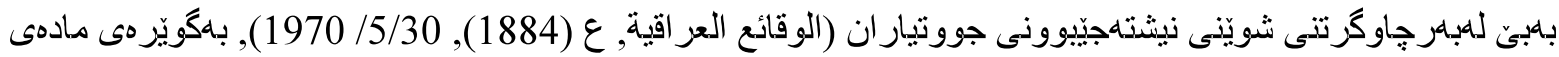

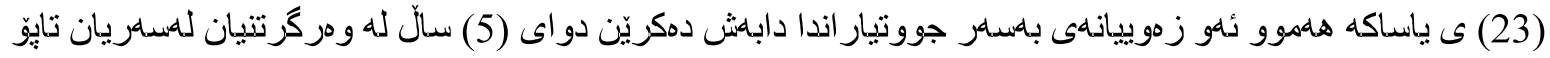

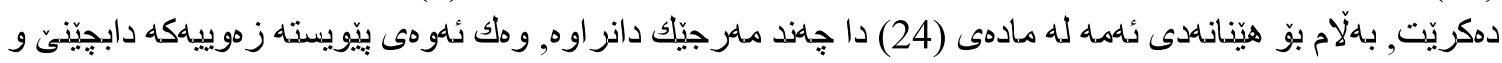

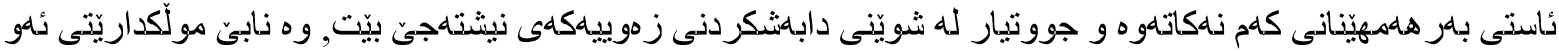

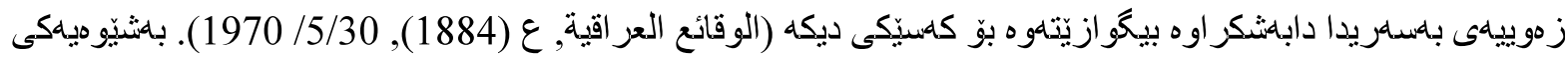

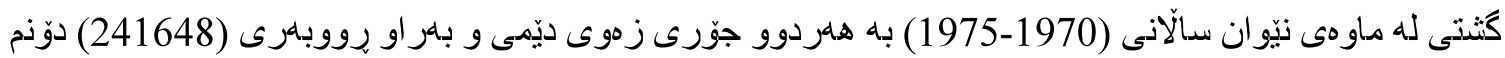

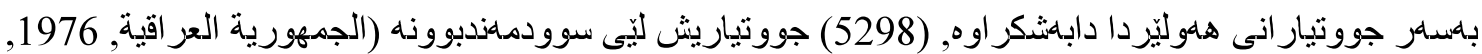

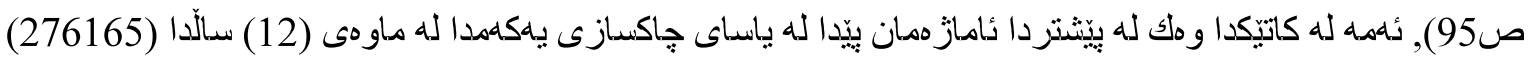

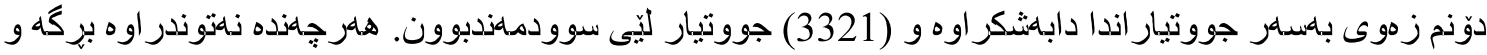

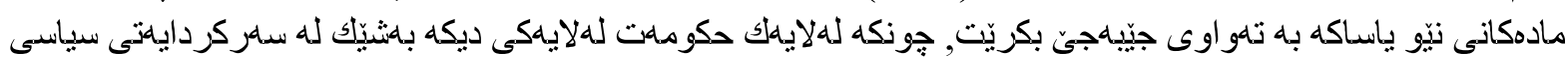

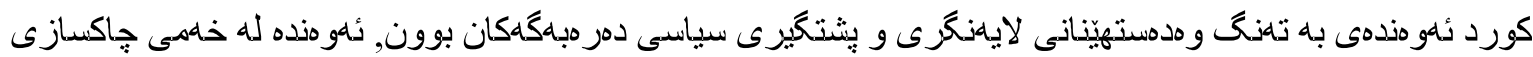

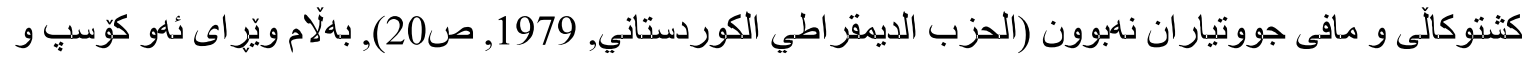

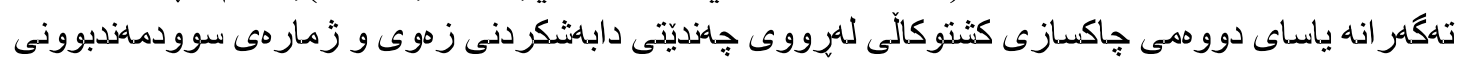

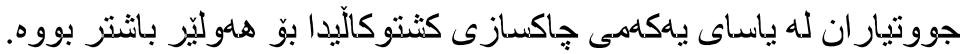

ئلزجام:

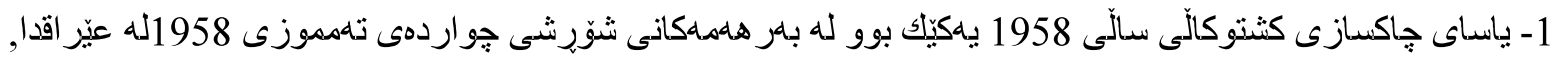

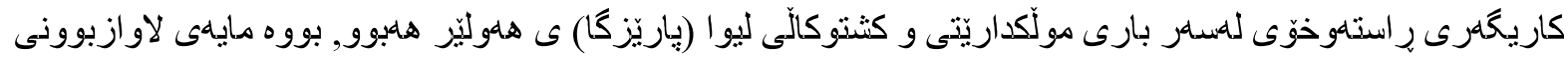

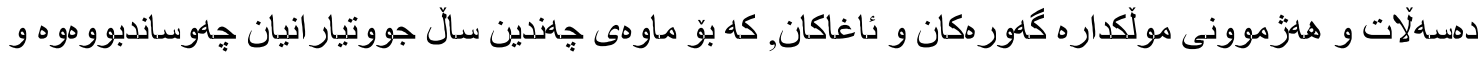

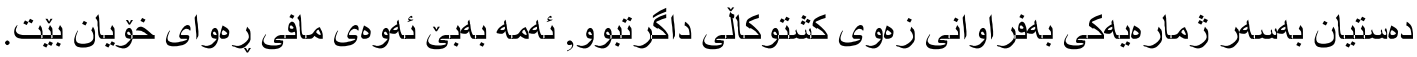

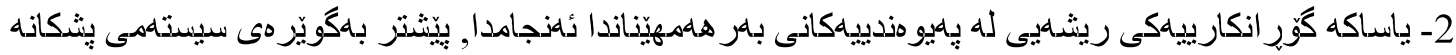

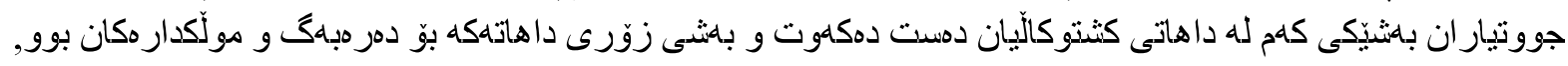

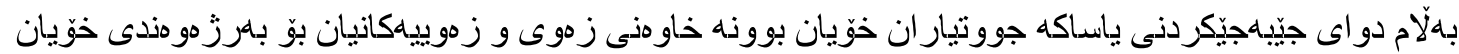




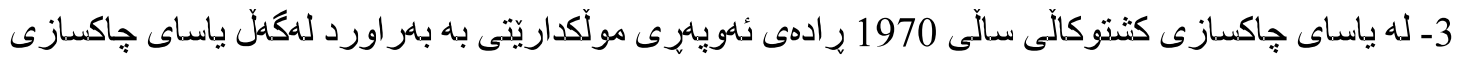

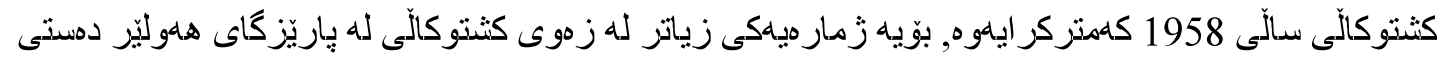

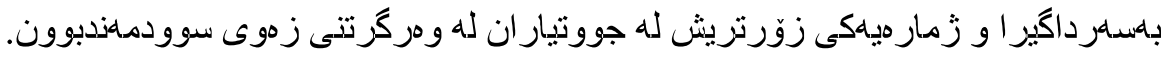

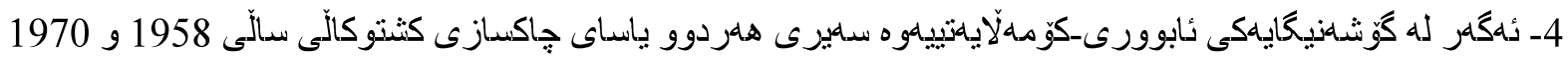

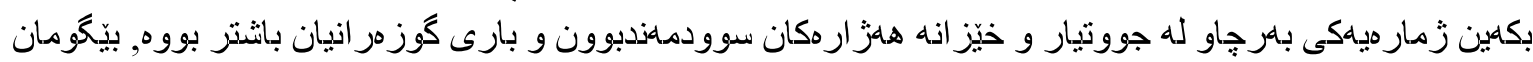

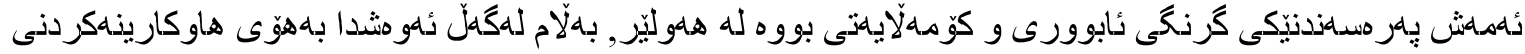

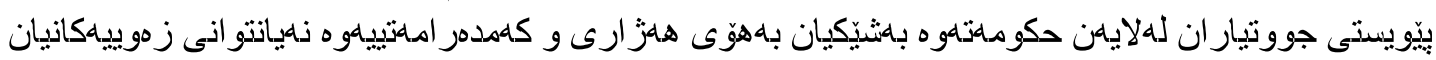

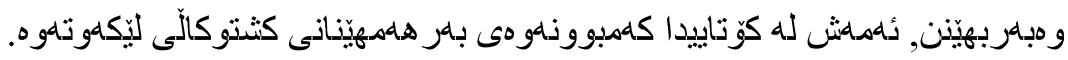
ليستى سلرجاو كان:

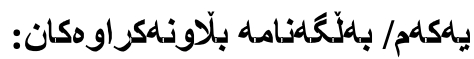

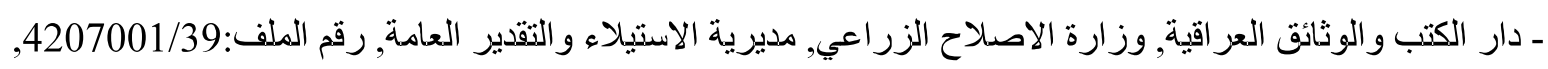

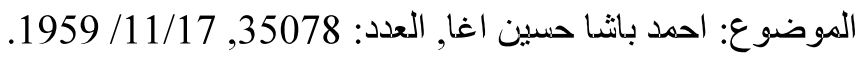

ـ دار الكتب و الوثائق العر اقية, الهيئة العليا للاصداح الزراعي, السكرتارية العامة, العنوان: تقدير ار اضي حمد احمد باثثا, العدد:1029, العئ

ـ دار الكتب و الوثائق العز اقية, وزارة الاصلاح الزر اعي, مديرية الاستيلاء و التقدير العامة, رئاسة لجنة التقدير في اربيل,

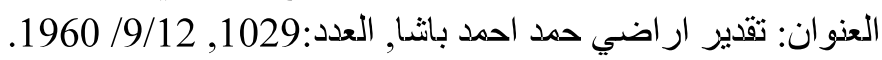

ـ دار الكتب و الوثائق العز اقية, وزارة الاصلاح الزر اعي, مديرية التوزيع العامة, الامور الفنية, الدوضوع: مذكرة بشأن

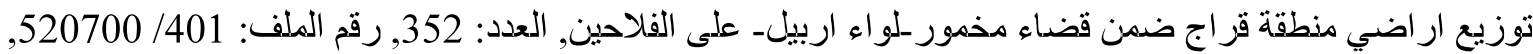
.1962/5/28

ـ أرشيف محافظة أربيل, وزارة الاصدلاح الزر اعى, مديرية الاصداح الزراعي في اربيل, القلم السري, الموضوع: مباثشرة

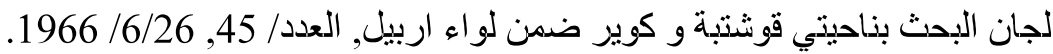

ـ أرشيف محافظة أربيل, قيادة الفرقة الاولى, الاركان العامة, سري للغاية, الموضوع: تأييد معلومات, الرقم: 2769, $.1966 / 11 / 16$

ـ أرشيف محافظة أربيل, الامن العامة, مديرية امن لواء اربيل, القلم السري, رقم الاضبارة: 87 87 الموضدوع: الوضع فى

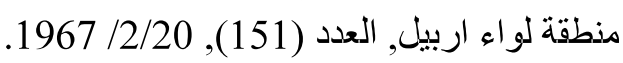
دووهم/ جإيكراوه حكومى و حزبييهكان:

ـ الجمهورية العز اقية, وز ارة التخطيط, دائرة الاحصاء المزكزي, نتائج الاحصاء الزر اعي و الحيواني في العز اق لسنة 1959-1958, مطبعة الحكومة, بغداد, 1961.

ـ الجمهورية العز اقية, لجنة الاحتفالات بالذكرى الثالثة لقانون الاصدلاح الزراعي, مطبعة المساحة, بغداد, 1962. ـ مديرية التوجيه و النشر فى وزارة الاصلاح الزر اعي, الاصلاح الزراعي فى اعوامه الثلاثة, شركة التجارة و الطباعة, بغداد, 1962.

ـ العيئة العليا للاصدلاح الزر اعي, قو انين الاصدلاح الزر اعي / قانون الاصدلاح الزر اعي رقم 30 لسنة 1958 وتعديلاته

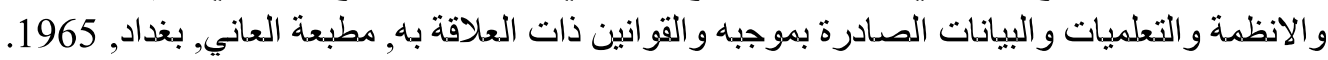


ـ الجمهورية العز اقية, وزارة الزر اعة, مديرية الديوان العامة, دليل القطاع الزر اعي فى العز اق لعامي 1968-1969, مطبعة وزارة الزر اعة, بغداد, 1970.

ـ الجمهورية العز اقية, وزارة التخطيط, الجهاز المزكزي للاحصاء, المجموعة الاحصائية السنوية 1970, مطبعة الجهاز المزكزي للاحصاء, بغداد, 1971.

ـ الجمهورية العز اقية, وزارة التخطيط, الجهاز المزكزي للاحصاء, نتائج التعداد الزر اعي العام لسنة 1971, ج1, مطبعة الجهاز المزكزي للاحصاء, بغداد, 1973.

ـ الجمهورية العز اقية, وزارة التخطيط, الجهاز المزكزي للاحصاء, المجموعة الاحصائية السنوية 1975, مطبعة الجهاز المزكزي للاحصاء, بغداد, 1976.

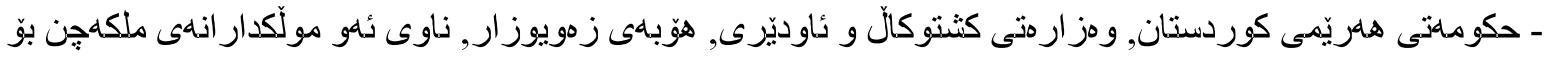

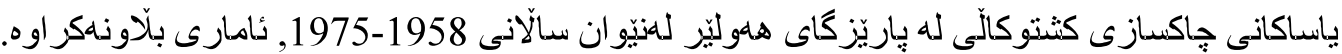

ـ الحزب الديمقر اطي الكوردستاني, طريق الحركة التحررية الكردية, التقزيز السياسي المصادق عليه من قبل كونفز اس

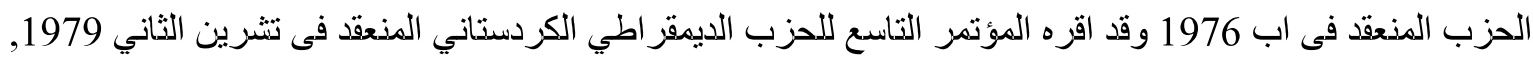

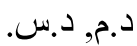

-

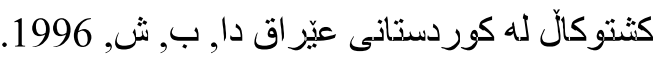

سيزيلم/ ياداشت و بيزهوهرييلكان:

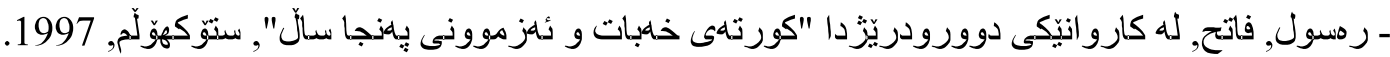

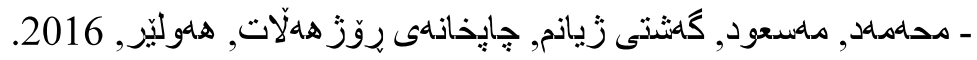

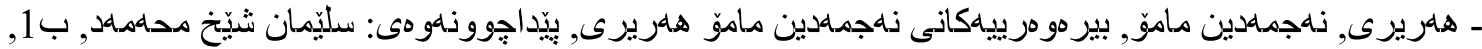

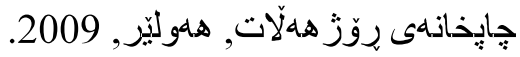

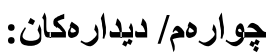

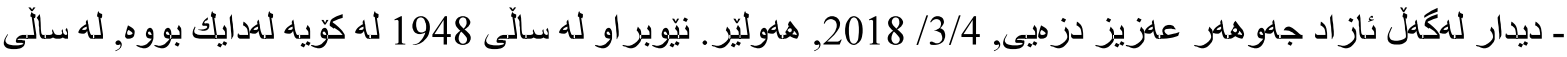

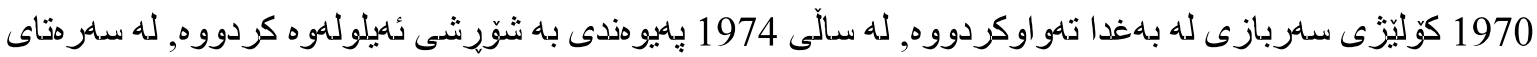

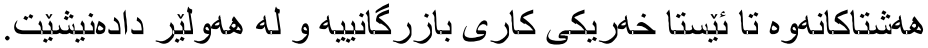

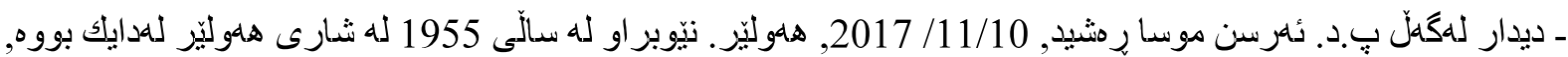

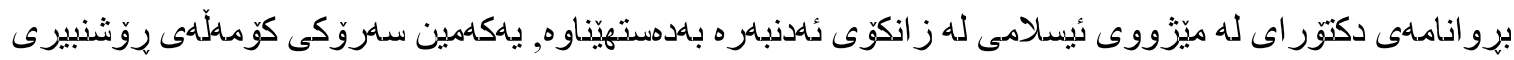

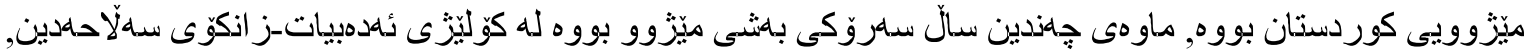

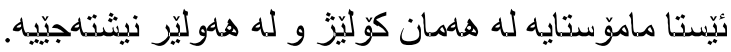

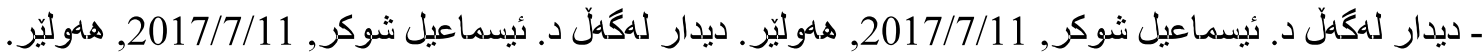

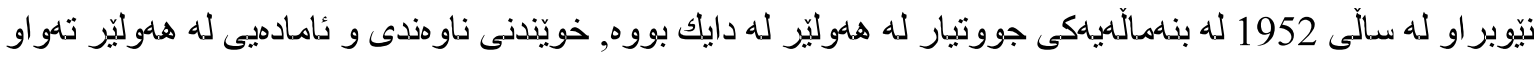

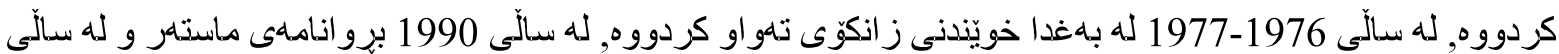

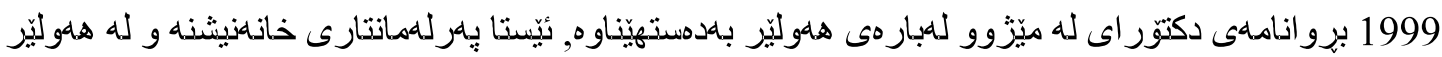




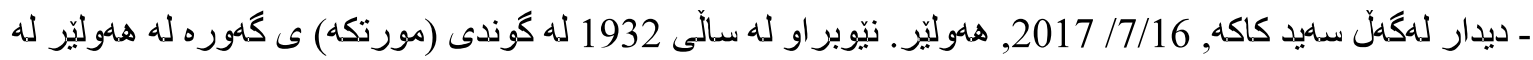

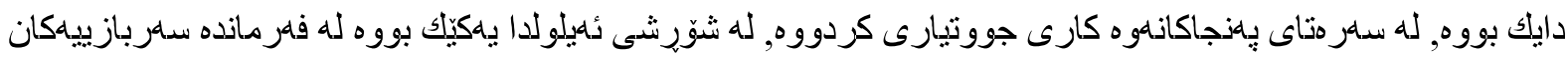

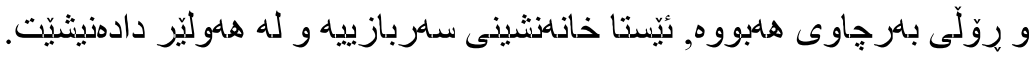

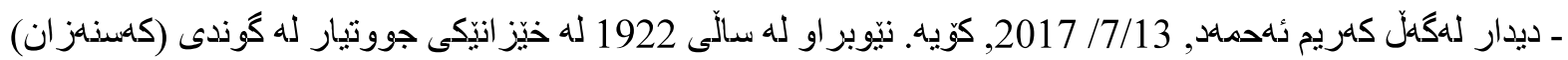

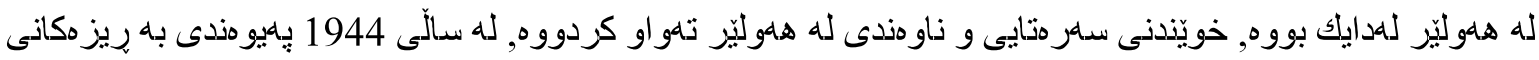

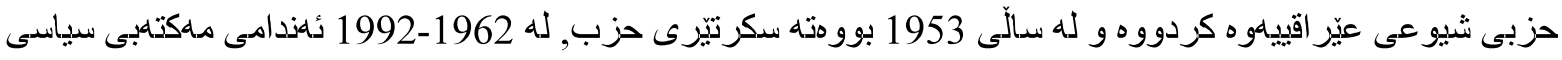

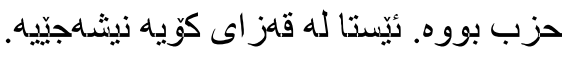

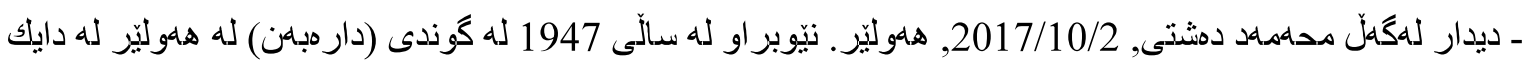

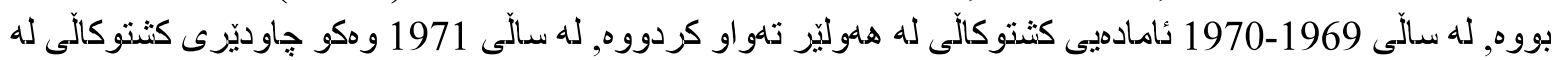

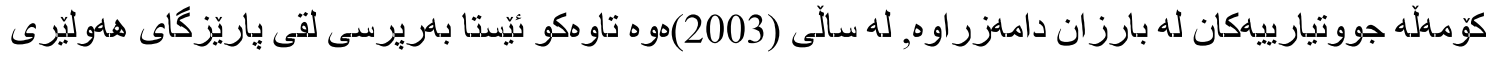

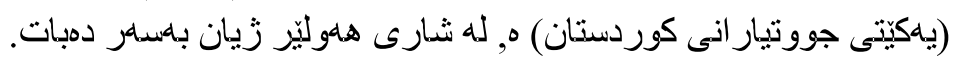

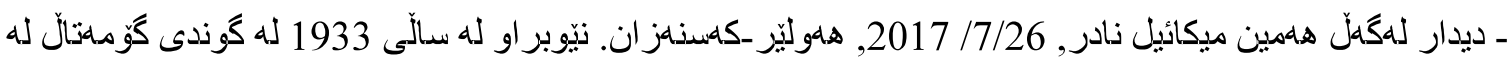

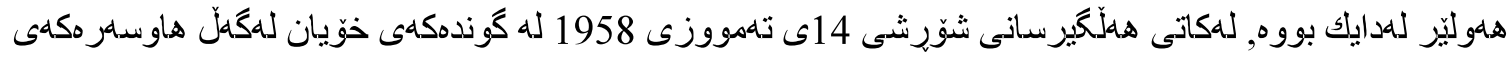

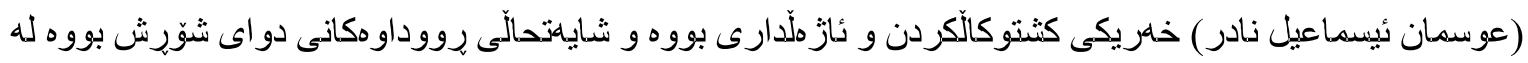

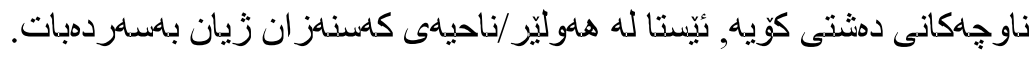

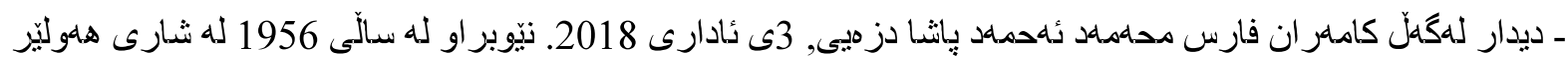

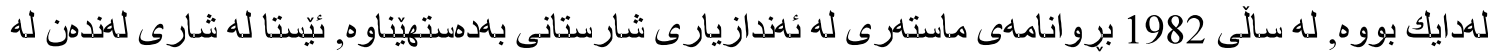
بريتانيا زيان باسلودردبات. بيّنجهم/ نامه و تيزه زانستييهكان:

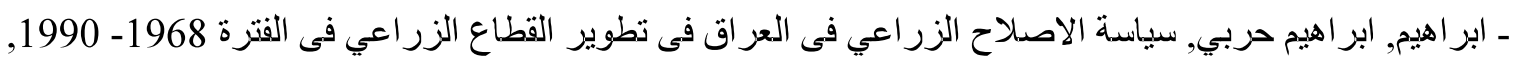
رسالة ماجستير غير منشورة, المعهد العالى للدر اسات السياسية والدولية, الجامعة المستنصرية, 2004. ـ البياتي, علي خليل, الاوضاع الاقتصادية في العز اق 1932-1939, رسالة ماجستير غير منثورة, كلية الاداب, جامعة بغداد, 1990.

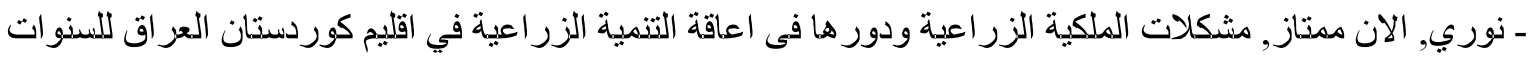

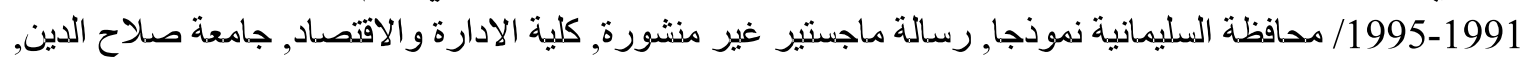

\section{شاهشهم/ كتيبلكان:

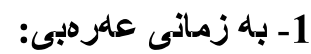

- بادى, ميّقان عارف, الحركة القومية الكوردية التحررية في كوردستان العزاق 1958-1963, مطبعة وزارة التربية, اربيل, 2005.

حبيب, كاظم, در اسات فى الاصداح و التعاون الزر اعي الانتاجي, الجامعة المستنصرية, بغداد, 1976. حبيب, كاظح, لمحات من نضال حركة التحرر الوطني للثعب الكردي في كردستان العراق, دار ئار اس للطباعة والنشر, اربيل, 2005. 
ـ الحفيد, صلاح الدين محمد, الوضع الاقتصادي في كردستان العزاق وأهم مشاكله, ج2/ اقتصاديات محافظة اربيل, مطبعة

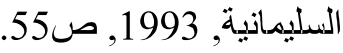
ـ الداهزي, عبدالو هاب مطر, اقتصاديات الاصدلاح الزر اعي, هطبعة العاني, بغداد, 1970. - رحمة, منى, السياسات الزر اعية في البلدان العزبية, مركز در اسات الوحدة العزبية, بيروت, 2000. - رسول, اسماعيل شكر, أربيل/ در اسة تأريخية في دور ها الفكري و السياسي 1939-1958, مطبعة بينايى, السليمانية, .2005

ـ الزبيدي, ليث عبدالحسين جواد, ثورة 14 تموز 1958 في العز اق, دار الحزية للطباعة, بغداد, 1979. ـ سباهي, عزيز, مو اقف من المسألة الزر اعية في العر اق, دار الزواد المزدهرة للطباعة و النشر والتوزيع والاعلان, بغداد,

- شريف, طارق ابر اهيح, شخصيات تتذكر, مطبعة الثقافة و الثباب, اربيل, 1988. ـ العاني, نورى عبدالحميد و الحربي, علاء جاسم محمد, تاريخ الوزارات العز اقية في العهد الجمهوري 1958-1968, ج1, ط2, بيت الحكمة, بغداد, 2005.

ـ العاهزي, راهي مز هز, مسدود محمد ودوره السياسى في العز اق 1919-1968 در اسة تاريخية, مر اجعة و تقديم: د. كمال مظهز أحمد, مطبعة دار الدور اء, بغداد, 2008.

ـ العلوان, عبد الصاحب, در اسات فى الاصدلاح الزراعي, مطبعة الاسواق التجارية, بغداد, 1961. ـ قادر, جبار و جامباز, طارق, قز ار ات مجلس قيادة الثثرة المنحل الخاصة بالكورد وكوردستان, مطبعة الحاج هاثثح, اربيل, 2013.

ـ كزم, عبدالو احد, في الاصلاح الزر اعي / در اسة مقارنة لقوانين الاصدلاح الزر اعي في العز اق وسورية ومصر, مطبعة الاداب, النجف, ابدر 1972.

ـ محمد, شيرز اد زكريا, مجلس قيادة الثورة في كوردستان_العز اق 1964-1970 در اسة تاريخية سياسية عامة, تقديم ومر اجعة: د. عبدالفتاح على البوتانى, مطبعة جامعة دهوك, دهرة دهو كورد, 2010.

ـ و ادي العطية, عبدالحسين, الاصلاح الزر اعي في العزاق و التنمية الاقتصدادية, مطبعة المعارف, بغداد, 1965.

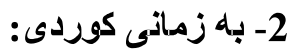

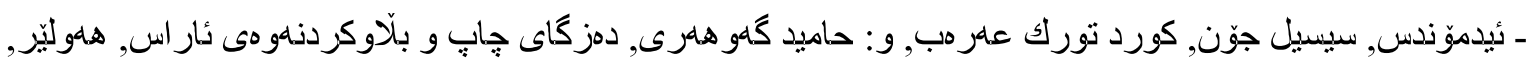
2004

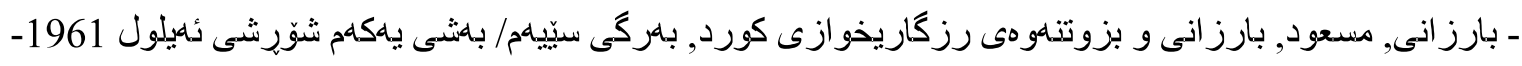

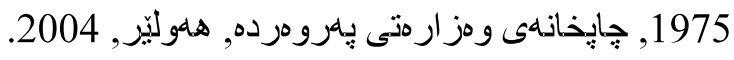

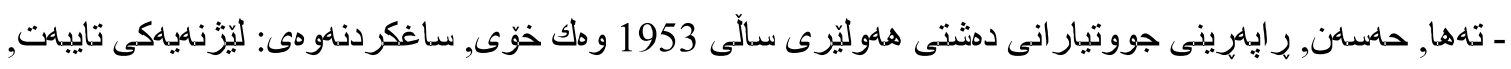
هلوليّر, 2002.

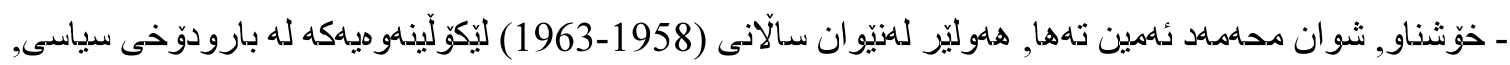

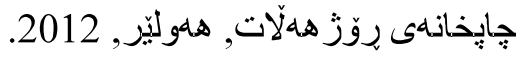




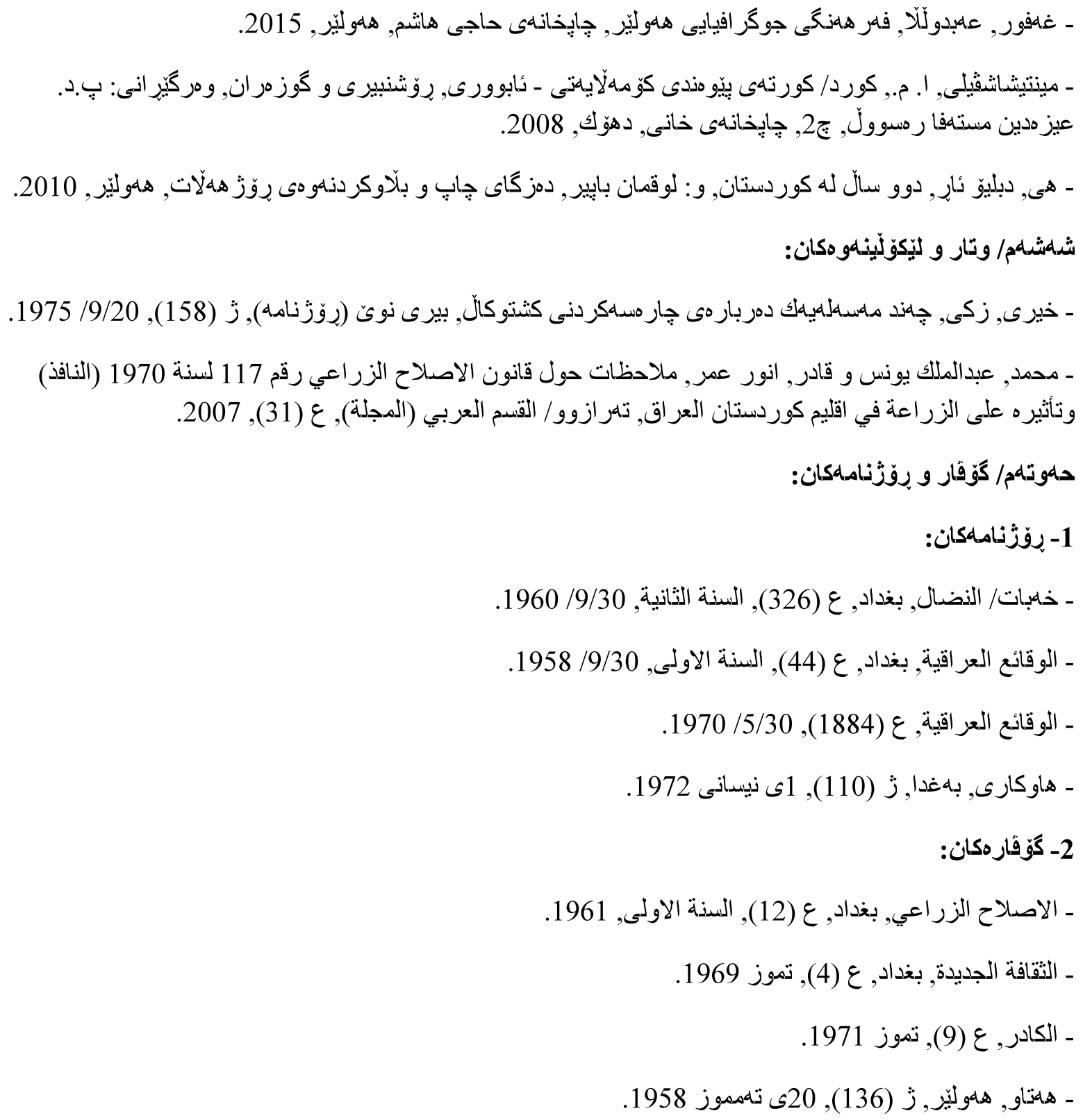

\section{References}

\section{Unpublished Documents:}

Iraqi National Library Archives, Ministry of Agrarian Reform, Directorate of Seizure and General Estimation, File No: 39-4207001, Subject: Ahmed Pasha Husein Agha, No: $35078,17 / 11 / 1959$.

Iraqi National Library Archives, Supreme Commission for Agrarian Reform, General Secretariat, Subject: Estimation the Lands of Hamad Ahmed Pasha, No: 1029, $5 / 6 / 1960$. 
Iraqi National Library Archives, Ministry of Agrarian Reform, Directorate of Seizure and General Estimation,the Presidency of Estimation Committee in Erbil, Subject: Estimate the Lands of Hamad Ahmed Pasha, No: 1029, 12/9/1960.

Iraqi National Library Archives, Ministry of Agrarian Reform, Directorate of General Distribution, Subject: Distribution the Lands of Qaraj Area within the Makhmour district - the Liwa of Erbil - on the Farmers, No: 401-520700, 28/5/1962.

Erbil Governorate Archive, Ministry of Agrarian Reform, Directorate of Agrarian Reform in Erbil, The Secret Office, Subject: Commencment of the Work of Research Committees in Qushtaba and Guer districts within the Erbil Liwa, No: 45, 26/6/1966.

Erbil Governorate Archive, Command of the First Division, General Staff, Secret, Subject: Information Support, No: 2769, 16/11/1966.

Erbil Governorate Archive, Public Security, Directorate of Erbil Liwa Security, The Secret Office, Subject: Situation in the area of the Erbil Liwa, No: 151, 20/2/1967.

\section{Government and Political Parties publications:}

Republic of Iraq, Ministry of Planing, Central Statistics Department, Results of agricultural and animal statistics in Iraq 1958-1959, Baghdad, 1961.

Repablic of Iraq, Committee for Celebrations of the Third Anniversary of the Law of Agrarian Reform, Al-Messaha Press, Baghdad, 1962.

Directorate of Guidance and Publishing in the Ministry of Agrarian Reform, Agrarian Reform in its Three Years, Trade and Printing Company, Baghdad, 1962.

Supreme Commission for Agrarian Reform, Agrarian Reform Laws / Agrarian Reform Law No. 30 of 1958 and its Amendments, and the regulations, instructions, statements issued thereunder and related laws, Al-Ani Press, Baghdad, 1965.

The Republic of Iraq, Ministry of Agriculture, Directorate of the General Office, Guide to the agricultural sector in Iraq for the years 1968-1969, Ministry of Agriculture Press, Baghdad, 1970. 
Republic of Iraq, Ministry of Planing, Central Statistical Organization, Annual Abstract of Statics 1970, Central Statical Organazation Press, Baghdad, 1971.

Republic of Iraq, Ministry of Planing, Central Statistical Organization, Results of 1971 Census of Agriculture, Part I, Central Statical Organazation Press, Baghdad, 1973.

Republic of Iraq, Ministry of Planing, Central Statistical Organization, Annual Abstract of Statics 1975, Central Statical Organazation Press, Baghdad, 1976.

Kurdistan Regional Government, Ministry of Agriculture and Irrigation, Names of land owners subject to the laws of Agrarian Reform in the Governorate of Erbil between the years 1958-1975, unpublished statistic.

Kurdistan Democratic Party, the Kurdish Liberation Movement, the political report ratified by the Conference Party held in August 1976 and approved by the 9th Conference of the Kurdistan Democratic Party in November 1979, without printing place and date .

Kurdistan Democratic Party, Political Bureau, Central Bureau for Studies and research, The Land problem and the reality of agriculture in Iraqi Kurdistan, without printing place, 1996.

\section{Theses and Dissertations:}

Al-Bayati, A. (1990). Economic Conditions in Iraq 1932-1939, unpublished M.A Dissertation. Faculty of Arts, University of Baghdad.

Ibrahim, I. (2004). Agrarian Reform Policy in Iraq in the Development of the Agricultural Sector 1968-1990. Unpublished M.A Dissertation, The Higher Institute of Political and International Studies. Mustansiriya University.

Nuri, A. (1996). Problems of Agricultural Ownership and its Role in Obstructing Agricultural Development in the Kurdistan Region of Iraq for the Years 1991-1995 / Sulaymaniyah Governorate, as a Model, Unpublished M.A Dissertation, Faculty of Administration and Economics. Salahuddin University.

\section{Books:}

\section{A. In Arabic:}


Al-Alwan, A. (1961). Studies in Agrarian Reform. Baghdad.

Al-Amiri, R. (2008). Masoud Mohammad and His Political Role in Iraq (1919-1968). A Historical study. Baghdad.

Al-Ani, N. (2005). History of the Iraqi Ministries in the Republican era 1958-1968. Baghdad.

Al-Atiyah, A. (1965). Agrarian Reform in Iraq and Economic Development. Baghdad.

Al-Dahiri, A. (1970). Economics of Agrarian Reform. Baghdad.

Al-Hafeed, S. (1993). The Economic Situation in Iraqi Kurdistan and its Most Important Problems. Part II / Economics of Erbil Governorate. Sulaymaniyah.

Al-Zubaidi, L. (1979). The Revolution of 14 July 1958 in Iraq. Baghdad.

Habib, K. (1976). Studies in Reform and productive agricultural cooperation. Baghdad.

Habib, K. Profiles from the Struggle of the National Liberation Movement of the Kurdish people in Iraqi Kurdistan. Erbil. 2005.

Kadir, J. (2013). Resolutions of the dissolved Revolution Command Council Relating to Kurds and Kurdistan. Erbil.

Karam, A. (1972). About Agrarian Reform / Comparative Study of the Laws of Agrarian Reform in Iraq, Syria and Egypt. Najaf.

Mevan, A.The Kurdish National Liberation Movement in Iraqi Kurdistan 1958-1963, Erbil, Education Ministry Press, 2005.

Rahma, M. (2000). Agricultural Policies in the Arab Countries. Beirut.

Rasoul, I. (2005). Erbil / A Historical Study in its Intellectual and Political Role 1939-1958. Sulaymaniyah.

Sabahi, A. (2009). Attitudes about the Agricultural Issue in Iraq. Baghdad. 2009.

Sherif, T. personalities remembering. Erbil.

Sherzad, Z. (2010). The Revolutionary Command Council of Kurdistan-Iraq 1964-1970. Ageneral Historical- Political Study. Dohuk. 


\section{B.In Kurdish:}

Barzani, M. (2004). Barzani and the Kurdish Libreration Movement, Part.3, Vol. 1, The September Revolation 1961-1975. Erbil.

Edmonds, S. (2004). Kurds, Turks and Arabs, Translated by: Hamid Gauhari. Erbil.

Ghafur, A. (2015). The geographical dictionary of Erbil. Erbil.

Hariri, N. (2009). Memoirs of Najmadin Mamo Hariri. Erbil.

Hay, W.R. (2010). Two years in Kurdistan. Translated by: Luqman Bapir. Erbil.

Khoshnaw, Sh. (2012). Erbil between the Years (1958-1963). A study in the Political Condition. Erbil.

Mentashashvili, A.M. (2008). The Kurds: A Summary of Social- Economic Relations, Culture and Living, Translated by: Izadden Mustafa Rasul. Duhok.

Muhamed, M. (2016). The Journey of My Life. Erbil.

Rasul, F. (1997). In a Far and Long Caravan. Stokholm.

Taha, H. (2002). The Uprising of the Farmers of Erbil Plain in 1953 as it is. Erbil.

\section{Articles and research:}

Khairy, Z. (September 1975). Issues on Agrarian Reform, Beri nwe (Newspaper). V: (158).

Mohammed, A. (2007). Notes on the Law of Agrarian Reform No. 117 of 1970 (effective) and its impact on agriculture in the Kurdistan Region of Iraq. Tarazw / Arabic Section (Magazine). V: (31).

\section{Magazines and newspapers:}

\section{A. newspapers:}

Al-Waqeeh Al-Iraqia, (1970). Baghdad, Vo: (44), 30 September 1958, Vo: (1884), 30 May

Hawkari, (1972). Baghdad, Vo: (110), 1 April

Khabat, (1960). Baghdad, Vo: (326), 30 September 


\section{B. Magazines:}

Al-Islah Al- Zirahi, (1961). Baghdad, Vo: (12)

Al-Thaqafa Al-Jadida, (1969). Baghdad, Vo: (4), July

Al-Kadir, (1971). Vo: (9), July

Hataw, (1958). Erbil, Vo: (136), 20 May

\section{Personal Interviews:}

Arsan, M. (2017). Personal Interview. November 10

Azad, J. (2018). Personal Interview. March 4

Hamen, M. (2017). Personal Interview.July 26

Ismail, Sh. (2017). Personal Interview. July 11.

Kamaran, F. (2017). Personal Interview. March 3

Karem, A. (2017). Personal Interview. July 13.

Muhamed, D. (2017). Personal Interview. October 2.

Said, K. (2017). Personal Interview. July 16. 